Article

\title{
Linking Soil Erosion Modeling to Landscape Patterns and Geomorphometry: An Application in Crete, Greece
}

\author{
Imen Brini ${ }^{1, *}$, Dimitrios D. Alexakis ${ }^{2} \mathbb{D}$ and Chariton Kalaitzidis ${ }^{1}$ \\ 1 Department of Geoinformation in Environmental Management, Mediterranean Agronomic Institute of \\ Chania, 73100 Crete, Greece; chariton@maich.gr \\ 2 GeoSat ReSeArch Lab, Institute for Mediterranean Studies, Foundation for Research and Technology \\ Hellas (FORTH) Rethimno, 74100 Crete, Greece; dalexakis@ims.forth.gr \\ * Correspondence: imen.brini@maich.gr
}

Citation: Brini, I.; Alexakis, D.D.; Kalaitzidis, C. Linking Soil Erosion Modeling to Landscape Patterns and Geomorphometry: An Application in Crete, Greece. Appl. Sci. 2021, 11, 5684. https://doi.org/10.3390/ app11125684

Academic Editor: Itzhak Katra

Received: 1 June 2021

Accepted: 16 June 2021

Published: 19 June 2021

Publisher's Note: MDPI stays neutral with regard to jurisdictional claims in published maps and institutional affiliations.

Copyright: (c) 2021 by the authors. Licensee MDPI, Basel, Switzerland. This article is an open access article distributed under the terms and conditions of the Creative Commons Attribution (CC BY) license (https:// creativecommons.org/licenses/by/ $4.0 /)$.

\begin{abstract}
Soil erosion is a severe and continuous environmental problem caused mainly by natural factors, which can be enhanced by anthropogenic activities. The morphological relief with relatively steep slopes, the dense drainage network, and the Mediterranean climate are some of the factors that render the Paleochora region (South Chania, Crete, Greece) particularly prone to soil erosion in cases of intense rainfall events. In this study, we aimed to assess the correlation between soil erosion rates estimated from the Revised Universal Soil Loss Equation (RUSLE) and the landscape patterns and to detect the most erosion-prone sub-basins based on an analysis of morphometric parameters, using geographic information system (GIS) and remote sensing technologies. The assessment of soil erosion rates was conducted using the RUSLE model. The landscape metrics analysis was carried out to correlate soil erosion and landscape patterns. The morphometric analysis helped us to prioritize erosion-prone areas at the sub-basin level. The estimated soil erosion rates were mapped, showing the spatial distribution of the soil loss for the study area in 2020. For instance, the landscape patterns seemed to highly impact the soil erosion rates. The morphometric parameter analysis is considered as a useful tool for delineating areas that are highly vulnerable to soil erosion. The integration of three approaches showed that there is are robust relationships between soil erosion modeling, landscape patterns, and morphometry.
\end{abstract}

Keywords: soil erosion; RUSLE model; landscape pattern; morphometry

\section{Introduction}

Soil erosion is one of the most important worldwide issues, which is caused mainly by natural factors (wind, water, and snow) and can be accelerated by anthropogenic activities [1], exceeding in some cases the amount of soil regeneration [2]. Accordingly, in some parts of the Mediterranean region, erosion is reaching an irreversible level, while in other places no more soil is left. In fact, as soil formation is a slow process, any soil erosion exceeding $1 \mathrm{t} \mathrm{ha}^{-1} \mathrm{yr}^{-1}$ can be considered irreversible within a time span of 50-100 years [3].

A representative example of the Mediterranean region is the island of Crete in Greece. Due to the intensification of olive culture and improper agricultural management practices by the olive farmers, significant land degradation and reductions in soil fertility have been noticed [4]. The above-mentioned inappropriate agricultural management, in combination with the Mediterranean climate and the topography, can seriously enhance soil erosion. Hence, spatial and quantitative assessments of soil erosion contribute to soil erosion control and conservation practices.

Soil erosion is defined by Kouli et al. [3] as the natural process of the transportation of soil particles across a given surface. Consequently, the soil loses its nutriments, which leads to poor soil fertility and productivity, significantly affecting the sustainability of 
agricultural land use. The average amounts of soil erosion all over the world are predicted to be around 12 to $15 \mathrm{t} \mathrm{ha}^{-1} \mathrm{yr}^{-1}$ [5].

The major physical factors that influence soil erosion are climate, topography, and soil characteristics. Land in the Mediterranean region is very susceptible to erosion due to its climate, characterized by dry summers, which weakens the soil, and mild to wet winters with heavy rainfall, which considerably erodes the topsoil, essentially in steep slope areas.

Since soil erosion is a worldwide concern, a number of models have been developed in the last decades in order to estimate soil erosion rates. Soil erosion modeling delivers both quantitative and qualitative assessments of the phenomenon regarding the different conditions [6,7]. The Revised Universal Soil Loss Equation (RUSLE) is the one most widely used to assess soil erosion rates. In fact, the RUSLE model integrates largely available data (such as rainfall, topographic maps, and satellites images) and provides consistent results.

The application of the RUSLE model in several catchments in Crete, Greece, showed consistent results compared to the findings for other Mediterranean catchments with similar characteristics. Furthermore, the RUSLE results were highly correlated with geomorphic, tectonic, and hydrolithological characteristics of the catchments $[3,8]$.

Further to the importance of the soil erosion issue, landscape fragmentation has the same significance in terms of environmental issues; thus, it is required to quantify the changes in landscape patterns due to soil erosion over time. Accordingly, landscape metrics represent a useful method to estimate the spatial landscape changes and fragmentation using satellite-based land cover classification. The analyses of the pattern changes through time enable the correlation between landscape patterns and soil erosion rates to be determined.

Recent studies have investigated the land cover compositions within catchments to detect variations in soil erosion and sediment yield. In fact, land cover patterns within a catchment can have a significant role in assessing the hydrological connectivity processes and sediment transportation; hence, determining the relationship between land cover patterns and soil erosion processes is essential for catchment management [9].

Since soil, landscape, and geomorphology are closely related, morphometric analysis is a useful method for identifying the major morphometric parameters that influence soil erosion and for defining the most threatened locations.

A recent study by Kumar Pradhan et al. [10] concluded that the morphometric analysis methodology is advantageous and cost-effective, especially for inaccessible areas (ungauged basins with limited data) in order to prioritize them regarding their susceptibility to soil erosion.

With the development of satellite observation technology, satellite remote sensing data have been extensively used to detect the changes caused by erosion and to estimate them quantitatively [11].

The main aim of this paper is to evaluate the relationship between soil erosion rates estimated from the RUSLE model and the landscape patterns and to draw conclusions regarding the most erosion-prone areas or sub-basins based on morphometric parameter analysis by combining remote sensing and geographic information system technologies with in situ data. As such, the specific objectives of this study are as follows:

(a) Estimate soil erosion rates using the Revised Universal Soil Loss Equation (RUSLE);

(b) Correlate soil erosion and landscape pattern using landscape metrics;

(c) Prioritize erosion-prone areas or sub-basins according to the morphometric parameter results.

From this point on, the paper is structured as follows. A brief description of the data and methods is given in Section 2. Section 3 represents the results of the RUSLE model for estimating soil erosion rates, the landscape metrics, and the morphometric parameters. These results are then discussed and used to identify the most susceptible areas to soil erosion that require further consideration. 


\section{Materials and Methods}

\subsection{Study Area}

The island of Crete is located in the southern part of Greece. It is the largest island in Greece, measuring $8336 \mathrm{~km}^{2}$ [12]. Crete is the most populated Greek island, with 623,065 inhabitants [13]. Consequently, over the last two decades, urban expansion and touristic activities have been increasing significantly. The topography of Crete consists mostly of mountainous terrain (with a mean elevation at $460 \mathrm{~m}$ ). The average slope is about $28 \%$. Soils in Crete are generally not very well developed and shallow [12]. Furthermore, it is characterized by a dry sub-humid Mediterranean climate (mild with warm and dry summers and slightly cold and humid winters). The mean annual temperature ranges between 15 and $20^{\circ} \mathrm{C}$, while the mean annual precipitation is estimated to be $750 \mathrm{~mm}$, varying spatially and temporally. In fact, rainfall intensity increases towards the western parts of the island during rainy seasons (autumn and winter). Rainfall intensity during spring is very low and is negligible during the summer.

According to Panagos et al. [12], Crete is mainly covered by natural grasslands and shrubs (46\%) and permanent crops (olives $23 \%$, vines $2.6 \%$, and citrus $0.7 \%$ ). Heterogeneous agricultural areas or fields mixed with natural vegetation cover $15.2 \%$ of the land, whereas a small share $(0.5 \%)$ is covered by greenhouses, arable land (irrigated or not), and pastures. Forest coverage represents less than $4 \%$ of the total area.

The specific study area is situated in the western part of Crete, specifically in the southwest of the Chania prefecture. It comprises two watersheds in the south of Chania (Paleochora region), named Pelekaniotis and Kakodikianos, as shown in Figure 1.
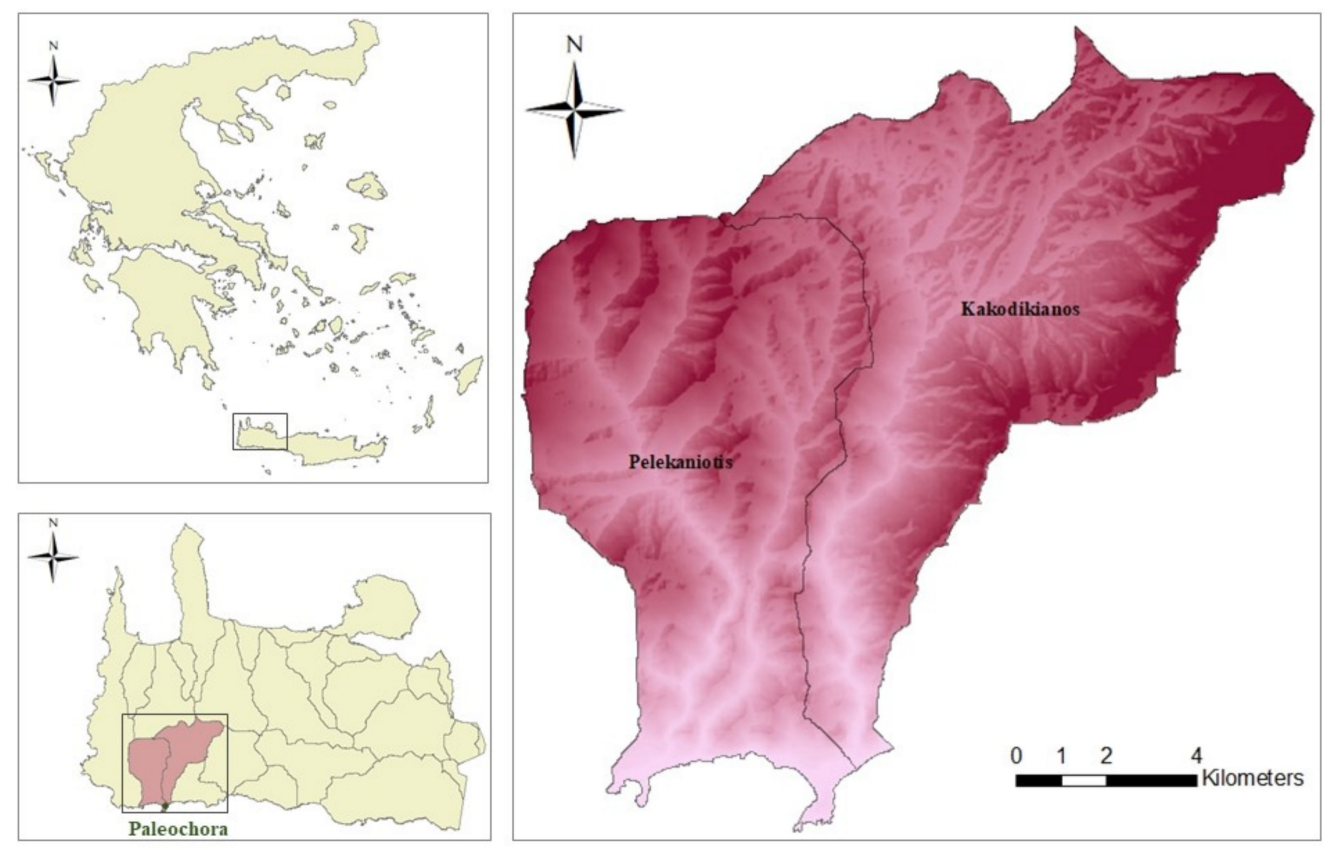

Figure 1. Shaded relief map of the study area.

\subsection{Data}

Different datasets were collected and analyzed to produce the factors of the RUSLE model. These datasets contained rainfall data, soil and topographical data, satellite imagery, and land use/land cover data.

The Integrated Multisatellite Retrievals (IMERG) for Global Precipitation Measurement (GPM) dataset for 2020 was downloaded from the National Aeronautics and Space Administration (NASA). In this study, the GPM_3IMERGDL v06 (D: daily, L: late run) products were employed, as they are widely used for research purposes and have enhanced accuracy. In fact, IMERG for GPM (IMERG) is the level 3 GPM algorithm, which integrates precipitation estimates from all constellation microwave (MW) sensors, IR-based sensors 
onboard geosynchronous satellites, and a monthly precipitation gauge product [14]. The spatial resolution of IMERG is $0.1^{\circ} \times 0.1^{\circ}$. In total, 4 grids covered the study area.

The LUCAS database includes particle size distributions expressed as percentages (\%) of clay $(0.0002-0.002 \mathrm{~mm})$, silt $(0.002-0.063 \mathrm{~mm})$, and sand $(0.063-0.2 \mathrm{~mm})$, as well as percentages of organic carbon $(\%)$ and coarse material $(>2 \mathrm{~mm})$ [15]. It was used to estimate the soil erodibility factor.

Since terrain morphology is an important factor in erosion, a digital elevation model (DEM) is essential for estimating various geomorphological parameters such as slope. The RUSLE requires a DEM as an input in order to quantitatively represent the continuous variation of topographic features across the landscape. The DEM generated from Radiometrically Terrain Corrected (RTC) Advanced Land Observing Satellite-Phased Array-type L-band Synthetic Aperture Radar (ALOS-PALSAR) data has a spatial resolution of $12.5 \mathrm{~m}$. The Radiometric Terrain Correction (RTC) corrects the geometric distortions using the best DEM available for the region of interest (SRTM DEM in this case) and also adjusts the radiometry in the affected foreshortening and layover regions using the pixel-area integration approach for radiometric normalization. ALOS-PALSAR DEM products have been used in the past to provide accurate results for soil erosion [16]. ALOS-PALSAR DEM data were downloaded from the Alaska Satellite Facility (ASF) and were used to derive the slope parameters (the slope length-steepness factor (LS-factor) and support practice factor (P-factor)). Prior to deriving the LS-factor from any space-borne DEM products, its accuracy must be evaluated [6]. The high accuracy of the ALOS-PALSAR DEM comes from applying high-quality DEMs (such as SRTM and the National Elevation Dataset (NED)) in radiometric and geometric corrections of PALSAR imagery [17].

The Sentinel-2 level 2A data were accessed on Google Earth Engine (GEE) provided by the European Space Agency (ESA). Level 2A is an ortho-image bottom-of-atmosphere (BOA)-corrected reflectance product according to the Sentinel-2 User Handbook [18]. The "ee.ImageCollection" GEE function was used to filter the time series data for the summer period of 2020 in order to avoid cloud cover.

Good Agricultural and Environmental Conditions (GAEC) promote the prevention of erosive farming practices (ploughing and planting up and down the slope) in mountainous areas and insist on the maintenance of landscape features, such as stone walls and terraces. In Greece, the farming practice for areas exceeding $10 \%$ slope is the cultivation along or diagonal to the contour (cross slope contour farming) in order to conserve rainwater and to reduce soil losses [19]. In Crete, the main conservation support practices are contour farming, stone walls, and grass margins [1]; thus, these three types of support practices were considered to estimate the P-factor. The following table (Table 1) summarizes the input dataset required for RUSLE model.

Table 1. Input datasets used in the Revised Universal Soil Loss Equation (RUSLE).

\begin{tabular}{cccc}
\hline Factors & Datasets & Data Source & $\begin{array}{c}\text { Spatial/Temporal } \\
\text { Resolution }\end{array}$ \\
\hline Rainfall erosivity & $\begin{array}{c}\text { GPM_3IMERGDL } \\
\text { v06 }\end{array}$ & Giovanni, NASA & $0.1^{\circ} \times 0.1^{\circ}$ Daily \\
\hline Soil erodibility & Soil structure & $\begin{array}{c}\text { European Soil } \\
\text { Database (ESDB) }\end{array}$ & - \\
\cline { 2 - 4 } & Soil properties & $\begin{array}{c}\text { LUCAS topsoil } \\
\text { database }\end{array}$ & \\
\hline $\begin{array}{c}\text { Slope length and } \\
\text { steepness }\end{array}$ & ALOS PALSAR DEM & $\begin{array}{c}\text { Alaska Satellite } \\
\text { Facility (ASF) }\end{array}$ & \multirow{2}{*}{$12.5 \mathrm{~m}$} \\
\hline Cover management & Sentinel-2 images & $\begin{array}{c}\text { “Copernicus” } \\
\text { program }\end{array}$ & $10 \mathrm{~m}$ \\
\hline Support practice & LUCAS observation & Eurostat & 2018 \\
\hline
\end{tabular}


For landscape metrics analysis, the land cover maps for the years 2010 and 2020 were derived from satellite imagery. For the year 2010, Landast-5 TM Collection 1 Tier 1-calibrated top-of-atmosphere (TOA) reflectance images were accessed on Google Earth EngineS (GEE) provided by USGS. These images were classified into different Corine Land Cover (level 3) classes. For the year 2020, the classified land cover map already derived for the cover management factor (C-factor) in RUSLE model were used to estimate the landscape metrics.

Concerning morphometric parameters analysis, ALOS PALSAR DEM was used to derive the basic morphometric parameters. The linear, shape, and relief parameters were extracted from the basic parameters.

\subsection{RUSLE Model}

\subsubsection{Model Description}

The RUSLE model predicts average annual erosion by water as a product of six parameters or factors (rainfall erosivity factor, soil erodibility factor, slope length and slope steepness factors, cover management factor, support practice factor) and is expressed as:

$$
A=R K L S C P
$$

where $A$ is the soil loss ( $\mathrm{t} / \mathrm{ha} /$ year), $R$ is the rainfall-runoff erosivity factor (MJ mm/(ha $\mathrm{h}$ yr)), $K$ is the soil erodibility factor ( $\mathrm{t}$ ha $\mathrm{h} /($ ha $\mathrm{MJ} \mathrm{mm})$ ), $L S$ is the slope length and steepness factor (dimensionless), $C$ is the cover management factor (dimensionless), and $P$ is the conservation support practice factor (dimensionless).

The R-factor is one of the key factors that influences water-prone erosion. It is expressed as a function of the rainfall amount and intensity. Basically, rainfall data are extracted from in situ measurements (meteorological gauge stations). Such data should be interpolated to gain a continuous spatial distribution and variability of rainfall. Despite their good accuracy, it is sometimes difficult to acquire data from inaccessible locations; thus, satellite data could be a potential alternative to derive rainfall data. In fact, many space-based mission were launched to monitor precipitation, such as the Tropical Rainfall Measurement Mission (TRMM) and the Global Precipitation Measurement (GPM) mission.

The K-factor is the erodibility factor, which indicates the intrinsic susceptibility of soil to water and runoff erosion. It depends mainly on the texture and structure of the soil. In fact, the RUSLE model takes into account the physical properties, such as the primary particle size distribution, organic matter, soil structure, and permeability, as the key factors affecting the erodibility of a soil. Initially, these properties were determined using laboratory-based methods [6]. At the European level, Panagos et al. [20] assessed soil erodibility based on properties (such as texture, organic carbon) that were available from the Land Use-Cover Area Frame Survey (LUCAS) topsoil data.

The LS-factor refers to the slope length (L) and the slope steepness (S). L reflects the distance from the point of origin of overland flow to the point where deposition begins. $S$ represents the slope gradient to designate flat, moderate, and steep slopes. Both slope length and steepness are proportional to erosion. Consequently, increases in L and S lead to higher runoff velocities and higher soil loss rates [1]. These topographic parameters are so sensitive to soil loss that a minor miscalculation could lead to inaccurate assessment of the overall soil erosion rates. Although this topographic factor is one of the principal factors for the RUSLE model, ground-based measurement data are usually unavailable. As an alternative to ground-based measurement, the LS-factor can be estimated using digital elevation models (DEMs) using geographic information system software [1,21].

The C-factor estimation distinguishes between arable lands and non-arable lands (all other land uses). Artificial areas, wetlands, water bodies, bare rocks, beaches, and glaciers are not included in the C-factor estimation [22]. The C-factor is defined as the ratio of soil loss under specific cover and management conditions to soil loss affecting an identical bare soil area [23]. It reflects the impacts of cropping and other management practices on the intensity of erosion. Traditionally, this factor was retrieved from field surveys; however, 
remote-sensing-based methods, such as land use/land cover (LULC) classifications; and spectral indices such as the Normalized Difference Vegetation Index (NDVI), Soil-Adjusted Vegetation Index (SAVI), and others, have been proven to be informative in deriving the C-factor [6].

The P-factor is the ratio of soil loss following a specific support practice to the corresponding soil loss after up and down cultivation [24]. It expresses the overall effects of different support practices, such as contour farming, stone walls, and terracing, on soil loss at a specific site. Those practices influence water erosion by changing the flow pattern or direction of surface runoff and by decreasing the volume and rate of runoff. The value of the P-factor is reduced when implementing these supporting conservation practices. Typical values range from 0 to 1 . In fact, the lower the P-factor value, the more effective the support practice is at attenuating soil erosion $[19,25]$; however, a value of 1 is assigned to areas where there are no supporting conservation practices.

\subsubsection{Implementation of RUSLE Model}

Rainfall Erosivity (R) Factor

The R-factor for any given period is obtained by summing for each rainstorm the product of total storm energy $(E)$ and the maximum 30 min intensity $\left(I_{30}\right)$ according to the standard equations used by Renard and Freimund [26]. Since detailed rainstorm data are rarely available at standard meteorological stations, daily, monthly, and annual rainfall amounts are often used to estimate the R-factor for the RUSLE.

Furthermore, de Santos Loureiro and de Azevedo Coutinho [27] developed a simple threshold-type regression model that uses daily rainfall data to estimate monthly rainfall erosivity. Their equation was then calibrated and validated for Crete by Grillakis et al. [28]. The equation considers the monthly rainfall for days with rain greater than $10 \mathrm{~mm}$, as well as the number of the days of month with rainfall greater than $10 \mathrm{~mm}$, as follows:

$$
R=\frac{1}{n} \sum_{j=1}^{n} \sum_{k=1}^{m j}\left(7.5 \times R_{10}-150 \times D_{10}\right)_{k, j}
$$

where $R_{10}$ is the total rainfall within a month $(\mathrm{mm})$, only for the days with rainfall $>10.0 \mathrm{~mm}$ (otherwise, set to zero); $D_{10}$ is the number of days with rainfall $>10.0 \mathrm{~mm}$; $n$ is the number of days covered by the rainfall data; $k$ is the individual erosive events for each month $j$; and $m j$ is the total number of erosive events for each month.

The spatial resolution of the downloaded GPM_3IMERGDL v06 (D: Daily, L: Late run) products is $0.1^{\circ} \times 0.1^{\circ}$. Consequently, these datasets were downscaled to $10 \times 10 \mathrm{~m}$. In their studies, Alexakis and Tanis [29] and Zhan et al. [30] downscaled the TRMM and GPM datasets, respectively, assuming that the precipitation and other environmental factors (vegetation, topography, albedo, and drought) are strongly related. The downscaling process can be expressed by:

$$
P=f\left(X_{i}\right)+\varepsilon
$$

where $P$ is downscaled precipitation, $X_{i}$ represents environmental variables, and $\varepsilon$ is the residual.

The general approach is to establish a correlation function $(f)$ between precipitation and environmental variables at coarse resolution and then to use the fine-resolution environmental variable as inputs of $(f)$ to predict precipitation at fine resolution. Consequently, the downscaled precipitation data are estimated through the equation below:

$$
P_{\text {downsclaed }}=P_{\text {estimated }}+P_{\text {residual }}
$$

where $P_{\text {downscale }}$ is the downscaled precipitation, $P_{\text {estimated }}$ is the high spatial resolution precipitation estimated from various environmental factors, and $P_{\text {residual }}$ is the residual between estimated precipitation and GPM. 
For the west part of Crete, Alexakis and Tanis [29] concluded that the multiple linear regression (MLR) approach performed slightly better than artificial neural network analysis; hence, in this study, the MLR methodology was used for downscaling purposes. With this aim, DEM and NDVI were tested as explanatory variables in the MLR-based downscaling algorithms to downscale GPM monthly precipitation from $10 \mathrm{~km} \times 10 \mathrm{~km}$ to $10 \mathrm{~m} \times 10 \mathrm{~m}$ over the study area. The downscaling process was performed following certain analysis steps described previously by Alexakis and Tanis [29].

In order to achieve the MLR analysis, the least squares method was applied to determine the coefficients using the XLSTAT add-in for Microsoft Excel. This is a standard approach in regression analysis based on minimizing the sum of the squares of the residuals between the observed response and the fitted response. The typical form of the model is:

$$
P=a x+b
$$

where $P$ is the daily precipitation, $x$ is the DEM, $a$ is the DEM slope, and $b$ is the intercept.

The daily ground precipitation data for 2020 extracted from 5 stations in Chania prefecture were used to validate the downscaled products. In order to evaluate the downscaling method quantitatively, three different statistical methods were calculated, namely the root mean square error (RMSE), the bias, and the coefficient of determination $\left(\mathrm{R}^{2}\right)$ :

$$
\begin{gathered}
R M S E=\sqrt{\frac{\sum_{i=1}^{n}\left(P_{i}-O_{i}\right)^{2}}{n}} \\
\text { Bias }=\frac{\sum_{i=1}^{n} P_{i}}{\sum_{i=1}^{n} O_{i}}-1 \\
R^{2}=\frac{\sum_{i=1}^{n}\left[\left(P_{i}-\bar{P}\right)\left(O_{i}-\bar{O}\right)\right]}{\sqrt{\sum_{i=1}^{n}\left(P_{i}-\bar{P}\right)^{2}} \sqrt{\sum_{i=1}^{n}\left(O_{i}-\bar{O}\right)^{2}}}
\end{gathered}
$$

where $P_{i}$ is the downscaled precipitation and $\bar{P}$ is the mean precipitation, $O_{i}$ is the groundobserved precipitation and $\bar{O}$ is the mean ground-observed precipitation, and $n$ is the number of observations.

The daily temporal-resolution precipitation measurements were also used to derive the R-factor by applying Equation (2). In this study, the R-factor was estimated at the point level (precipitation stations). The predicted R-values were then extrapolated to the catchment level using ordinary kriging-based interpolation in the ArcGIS environment.

\section{Soil Erodibility (K) Factor}

The most commonly used equation to estimate the K-factor ( $\mathrm{t}$ ha h ha ${ }^{-1} \mathrm{MJ}^{-1} \mathrm{~mm}^{-1}$ ) was proposed by Wischmeier and Smith [24] and reported in the study by Panagos et al. [15]:

$$
K=\left[\left(2.1 M^{1.14}(12-O M) 10^{-4}+3.25(s-2)+2.5(p-3)\right) / 100\right] \times 0.1317
$$

where $M$ is the textural factor, with $M=\left(m_{\text {silt }}+m_{v f s}\right) \times\left(100-m_{c}\right) ; m_{c}(\%)$ is the clay fraction content $(<0.002 \mathrm{~mm}), m_{\text {silt }}(\%)$ is the silt fraction content $(0.002-0.063 \mathrm{~mm}), m_{v f s}(\%)$ is the very fine sand fraction content $(0.063-0.1 \mathrm{~mm}), O M(\%)$ is the organic matter content, $s$ is the soil structure class, and $p$ is the permeability class.

The suggested erodibility equation can only be recommended if the organic matter content is known and the silt content is below 70\%. Panagos et al. [15] mentioned that if both criteria are met, this equation is more precise than other equations.

Additionally, in the literature, the sand fraction is classified into five classes: very fine, fine, medium, coarse, and very coarse. The very fine sand structure $(0.05-0.1 \mathrm{~mm})$ as a sub-factor $\left(m_{v f_{s}}\right)$ in Equation (9) is estimated as $20 \%$ of the sand fraction $(0.063-2.0 \mathrm{~mm})$; 
this information is available in the LUCAS topsoil database. In the European Soil Database, soil structure is categorized as humic, poor, normal, or good, as shown in Table 2.

Table 2. Soil structure according to the European Soil Database.

\begin{tabular}{cccc}
\hline Structure Class & Description & Granular Size & European Soil Database \\
\hline 1 & Very fine granular & $1-2 \mathrm{~mm}$ & Good \\
\hline 2 & Fine granular & $2-5 \mathrm{~mm}$ & Normal \\
\hline 3 & Medium or coarse granular & $5-10 \mathrm{~mm}$ & Poor \\
\hline 4 & Blocky, platy, or massive & $>10 \mathrm{~mm}$ & Humic \\
\hline
\end{tabular}

This dataset was used to determine the structure class values needed for K-factor calculation. In this study, and according to the ESDB, the soil structure was good, corresponding to a very fine granular soil structure; thus, the structure class was 1 .

In order to determine the permeability class values, the percentage of the soil content (sand, silt, and clay) were plotted in the textural triangle diagram to define the soil texture. According to this classification, the corresponding permeability class was assigned (Table 3).

Table 3. Soil permeability.

\begin{tabular}{ccc}
\hline Permeability Class & Description & Texture \\
\hline 1 & Fast and very fast & Sand \\
2 & Moderate fast & Loamy sand, sandy loam \\
3 & Moderate & Loam, silty loam \\
4 & Moderate slow & Sandy clay loam, clay loam \\
5 & Slow & Silty clay loam, sand clay \\
6 & Very slow & Silty clay, clay \\
\hline
\end{tabular}

In this study, the soil texture was silty clay loam corresponding to permeability class 5 . Once the K-values were calculated for every LUCAS point, they were interpolated to a map using the inverse distance weighting (IDW) method. The IDW is based on the assumption that the soil erodibility at an unsampled point is a distance weighting average of soil erodibility values of the nearby sampling points.

\section{Slope Length-Steepness (LS) Factor}

To extract the LS-factor, many algorithms are already built into GIS software programs, such as the System for Automated Geoscientific Analyses SAGA GIS [31]. In fact, SAGA provides numerous combinations of algorithms to derive the topographic data and preprocessing algorithms to fill sinks or for sink removal. In this study, the LS calculation was executed using the original equation proposed by Desmet and Govers [32], which incorporates a multiple flow algorithm and contributes to a precise estimation of flow accumulation.

Many researchers worldwide use algorithms proposed by Desmet and Govers [32] based on the DEM resolution and unit contributing area (UCA). These algorithms allow the model to be adapted to varied reliefs and include the influence of flow concentration.

The calculation methodology for the LS-factor was applied to each pixel in the DEM. The $\mathrm{L}$ factor is expressed according to the equation proposed by Desmet and Govers [32].

$$
L_{i, j-i n}=\frac{\left(A_{i, j-i n}+D^{2}\right)^{m+1}-A_{i, j-i n}^{m+1}}{D^{m+2} \times x_{i, j}^{m} \times 22.13^{m}}
$$

where $L i, j-i n$ is the slope length for grid cell $(i, j), A i, j-i n$ is the contributing area at the inlet of the grid cell with coordinates $(i, j)\left(\mathrm{m}^{2}\right), D$ is the grid cell size $(\mathrm{m}), m$ is the length exponent 
of the USLE L-factor, $x i, j$ is the summation of the sine and cosine of the aspect direction $\left(\alpha_{i, j}\right)$ of the grid pixel $x_{i, j}=\sin \alpha_{i, j}+\cos \alpha_{i, j}$, and 22.13 is the length of the USLE unit plot in meters.

In attempts to calculate the upslope contributing area $(A i, j-i n)$ for each pixel, several algorithms have been developed and are reported in the literature. The exponent $(m)$ was implemented according to the algorithm proposed by McCool et al. [33], where the slope length is a function of the rill-to-interrill $(\beta)$ erosion ratio, as expressed in the following equation:

$$
m=\beta /(\beta+1)
$$

where $\beta$ varies according to the slope gradient [33]. The $\beta$ value is obtained as:

$$
\beta=\frac{\frac{\sin \theta}{0.0896}}{\left[0.56+3(\sin \theta)^{0.8}\right]}
$$

where $\theta$ is the slope in degrees.

The calculation of the S-factor proposed by Wischmeier and Smith [24] was adjusted in the RUSLE model for a better representation of the slope steepness factor, which takes into account the ratio of the rill and interrill erosion:

$$
\begin{gathered}
S=10.8 \sin \theta+0.03, \theta<9 \% \\
S=16.8 \sin \theta-0.5, \theta \geq 9 \%
\end{gathered}
$$

where $\theta$ is the slope angle.

\section{Cover Management (C) Factor}

Remote-sensing-based methods such as land use/land cover (LULC) classification and spectral indices such as the Normalized Difference Vegetation Index (NDVI), Soil-Adjusted Vegetation Index (SAVI), and others, have been proven to be informative in deriving the C-factor.

LULC classification is one of the most used methods to derive the C-factor. In fact, after determining the LULC classes from the remotely sensed data, corresponding C-factor values were assigned from the literature. Generally, the $\mathrm{C}$-factor ranges between 0 and 1 ; areas with sparse vegetation tend to have higher $C$ values due to the effect that low vegetation cover has on erosion, while areas with dense vegetation have values close to 0 due to limited soil erosion [34].

Machine learning algorithms, such as Classification and Regression Trees (CART), Support Vector Machine (SVM), Minimum Distance (MD), and Random Forest (RF), have been proven to be relevant classifiers for land cover [35].

Spectral indices and their derivations (such as Fractional Vegetation Cover (FVC) derived from $N D V I$ ) were also used to evaluate the fraction of vegetation and its influence on C-factor values. In fact, they have the ability to enhance the spectral contribution of different vegetation cover types. Consequently, several empirical relations were established to correlate NDVI values to C-factor values. Commonly, NDVI is directly correlated to the C-factor by an exponential regression [36] or a linear regression [37].

The main aim is to derive the most relevant C-factor map from these methods. To do so, the above-mentioned classifiers were run followed by an accuracy assessment based on Google Earth free data to choose the best classification algorithm. Moreover, spectral indices were used to derive $\mathrm{C}$-factor values. In order to define the most reasonable values, the resulting $\mathrm{C}$-factor values obtained from different methods were compared between each other.

The satellite data (Sentinel-2 level 2A assets) were accessed on Google Earth Engine (GEE) provided by the European Space Agency (ESA). Images were filtered by a cloud cover percentage of less than $10 \%$. 
Corine was used to create a label dataset for training. GEE trains this dataset to recognize patterns in the image by selecting pixels that represent patterns or land cover features that it recognizes. Bands 4, 3, and 2 of Sentinel-2 images were combined to display false color composite images for better visualization of land cover. The land cover classes were compared to the Corine Land Cover (CLC) map. In order to overcome the problem of isolated pixels on the classified images, a post-classification process is recommended [38]. In this study, statistical filtering (majority filter process) was conducted, whereby isolated pixels were grouped into the closest value of the majority of their contiguous neighboring pixels.

Concerning the classification accuracy assessment, Google Earth is a powerful source of high spatial resolution data that can be used for investigation and preliminary studies with suitable accuracy and low cost. In this study, the accuracy assessment for the classified image was based on Google Earth imagery.

A set of 150 points were randomly generated and identified in Google earth, then the overall accuracy and Kappa statistics were estimated. In fact, the overall accuracy represents the probability that a pixel will be correctly classified, while the Kappa coefficient expresses the proportionate reduction in error generated by a classification process compared with the error of a completely random classification [39].

Once the classification was validated, the following $C$-factor values were assigned to each specific land cover type according to Panagos et al. [22] (Table 4).

Table 4. Assigned C-factor values from literature [22].

\begin{tabular}{ccc}
\hline \multicolumn{2}{c}{ Corine } & \multirow{2}{*}{ C-Factor } \\
\cline { 1 - 2 } Code & Label & 0.1307 \\
\hline 212 & Permanently irrigated land & 0.2094 \\
\hline 223 & Olive groves & 0.1132 \\
\hline 231 & Pasture & 0.1476 \\
\hline 242 & Complex cultivation patterns & 0.1307 \\
\hline 243 & Land principally occupied by agriculture with \\
& significant areas of natural vegetation & 0.0014 \\
\hline 311 & Broadleaf forest & 0.0014 \\
\hline 321 & Mixed forest & 0.0014 \\
\hline 323 & Natural grassland & 0.0014 \\
\hline 324 & Sclerophyllous vegetation & 0.026 \\
\hline 333 & Transitional woodland-shrubs & 0.3062 \\
\hline & Sparsely vegetated areas &
\end{tabular}

The NDVI is a commonly used spectral index that calculates the spectral reflectance difference between red and near-infrared bands of a satellite image according to the following equation:

$$
N D V I=\frac{(N I R-R E D)}{(N I R+R E D)}
$$

where NIR is the near-infrared band and RED is the red band of the satellite image.

The NDVI index ranges from -1 to +1 , with the highest values attributed to areas with greater vegetation cover [40].

Many empirical equations have been set up to correlate NDVI values to C-factor values. The C-factor can be derived using the equation proposed by van der Knijff et al. [36], C(vk), which was based on the positive correlation between the NDVI and C-factor in Europe:

$$
\mathrm{C}(\mathrm{vk})=e^{\left[-\alpha\left(\frac{N D V I}{\beta-N D V I}\right)\right]}
$$


where $\alpha$ and $\beta$ are parameters related to the shape of the curve that associates NDVI with the C-factor. Furthermore, van der Knijff et al. [36] assumed that for European climate conditions, an $\alpha$-value of 2 and a $\beta$-value of 1 seem to be best representative of the equation parameters.

Durigon et al. [37] suggested another equation based on NDVI rescaling, named the denominated rescaled $\mathrm{C}$-factor $(\mathrm{C}(\mathrm{r}))$. They found that this equation was more suitable for deriving $\mathrm{C}$-factor values under tropical climate conditions.

$$
\mathrm{C}(\mathrm{r})=\frac{-N D V I+1}{2}
$$

Furthermore, an improved vegetation-index-based method is available for evaluating the fractional vegetation cover. It efficiently distinguishes between areas of dense vegetation cover and sparsely vegetated areas.

$$
F V C(\%)=\frac{N D V I-N D V I_{\text {soil }}}{N D V I_{\text {veg }}-N D V I_{\text {soil }}} \times 100
$$

where $N D V I$ is the vegetation index of each pixel, $N D V I_{\text {soil }}$ corresponds to the vegetation index of a "pure" soil pixel, and $N D V I_{\text {veg }}$ corresponds to the vegetation index of a "pure" vegetation pixel.

It is necessary to determine the NDVI values for "pure" soil and vegetation pixels, respectively. Zhang et al. [41] mentioned that the $N D V I_{\text {soil }}$ value is around zero for a bare surface; however, this can vary depending on soil conditions (such as soil moisture, roughness, type, and color); thus, this value can be extracted based on the image data. Regarding the $N D V I_{\mathrm{veg}}$ value, this corresponds to the maximum value for all vegetation pixels. Similar to $N D V I_{\text {soil }}$, the $N D V I_{\text {veg }}$ value can change depending on the vegetation type, the seasonal change of the canopy, and other conditions.

In order to estimate these values, Jing et al. [42] proposed an approach based on the derived histogram of the NDVI data of the image. In fact, the NDVI value that accounted for $1 \%$ of pixels of the histogram was set as $N D V I_{\text {soil }}$, while the NDVI value that accounted for $99 \%$ of the pixels was set as $N D V I_{\text {veg. }}$. The NDVI histogram is plotted in the following figure.

In this study, $N D V I_{\text {soil }}$ was estimated as 0.102 and $N D V I_{\text {veg }}$ was estimated as 0.875 . Once the FVC map is derived, Jing et al. [42] recommended that pixels with negative values be adjusted to 0 and that pixels with values greater than 100 be adjusted to 100 .

As cited by Li et al. [43], the following equations represent the empirical relation between the $\mathrm{C}$-factor and the fractional vegetation cover for China:

$$
\mathrm{C}(\mathrm{FVC})=\left\{\begin{array}{cl}
1, & F V C=0 \\
0.6508-0.343 \log F V C, & 0<F V C<78.3 \% \\
0, & F V C \geq 78.3 \%
\end{array}\right.
$$

Support Practices (P) Factor

In Crete, the main conservation support practices are contour farming $\left(P_{c f}\right)$, stone walls $\left(P_{s w}\right)$, and grass margins $\left(P_{g m}\right)[1]$; thus, these three types of support practices were considered to estimate the P-factor according to the following equation:

$$
P=P_{c f} \times P_{s w} \times P_{g m}
$$

where $P_{c f}, P_{s w}$, and $P_{g m}$ are the P-factor values for contour farming, stone walls, and grass margins, respectively.

Contouring is a specific support practice applied only in croplands. The contour farming efficiency is influenced by the topographic slope. Wischmeier and Smith [24] assumed that contouring seems to be most effective on slopes ranging between 3 and 
8 percent. As such, according to the slope gradient, respective P-factor values were assigned (Table 5).

Table 5. P-factor values for contour farming practices for different slope gradients [19].

\begin{tabular}{cl}
\hline Slope (\%) & Pcf \\
\hline $1-2$ & 0.60 \\
\hline $3-5$ & 0.50 \\
\hline $6-8$ & 0.50 \\
\hline $9-12$ & 0.60 \\
\hline $13-16$ & 0.70 \\
\hline $17-20$ & 0.80 \\
\hline $21-25$ & 0.90 \\
\hline$>25$ & 0.95 \\
\hline
\end{tabular}

Commonly, stone walls and grass margins cause reductions in soil erosion rates by decreasing the velocity of the overland flow and sediment transport, respectively [1]. Dry stone walls are extensive landscape features in the Mediterranean preventing soil erosion, especially in hilly areas. In Greece, the density of stone walls exceeds 8\% [19]. Grass margins are strips of principally uncultivated land with vegetation dominated by grasses or herbs. They are mainly located at the borders of fields, between cropped areas or neighboring roads and pathways [19]. Table 6 represents the density values of stone walls and grass margins along a transect (LUCAS database) and assigned P-factor $\left(P_{s w}\right.$ is the stone walls sub-factor and $P_{g m}$ is the grass margins sub-factor) values for Europe.

Table 6. P-factor values for the stone walls sub-factor $\left(P_{s w}\right)$ and grass margins sub-factor $\left(P_{g m}\right)$ for the LUCAS database [19].

\begin{tabular}{ccccc}
\hline No of Features (SW or GM) & \% Sw & Psw & \% Gm & Pgm \\
\hline 0 & 0 & 1 & 0 & 1 \\
\hline 1 & 83.33 & 0.707 & 100 & 0.853 \\
\hline 2 & 0 & 0.577 & 0 & 0.789 \\
\hline 3 & 16.66 & 0.5 & 0 & 0.750 \\
\hline 4 & 0 & 0.448 & 0 & 0.724 \\
\hline 5 & 0 & 0.408 & 0 & 0.704 \\
\hline 6 & 0 & 0.378 & 0 & 0.689 \\
\hline 7 & 0 & 0.354 & 0 & 0.677 \\
\hline 8 & 0 & 0.334 & 0 & 0.667 \\
\hline$>8$ & 0 & 0.317 & 0 & 0.66 \\
\hline
\end{tabular}

In order to evaluate the effects of these features on a study area, spatial interpolation process should be executed. According to the objective of the study, which was to define the spatial patterns of stone walls and grass margins, and by referring to previous studies, the kriging approach was used for spatial interpolation. In fact, this method provides a spatially homogeneous surface with a constant variance and mean [19]. In this study, the ordinary kriging was based on 12 observation points for the radius setting.

As mentioned earlier and according to Equation (1), 5 different factors were organized in GIS raster grids with $10 \mathrm{~m}$ spatial resolution and then overlaid in the GIS environment. The final soil loss map was produced using the GISus-M plug-in module for ArcMap. This is an add-in for ArcGIS Desktop, which was built using an integrated development 
environment (IDE) and programmed in C\# with Microsoft Visual Studio 2010. The tool allows the construction of the databases and automatically performs the calculations in order to build the layers, which are the spatial maps of information used in the RUSLE. Finally, it calculates the potential soil erosion rates over the area of interest.

\subsection{Landscape Metrics Analysis}

The use of landscape metrics is a utile method for estimating the relationships between spatial patterns and spatial processes [44]. The analyses of the pattern changes through time enable the correlation between landscape patterns and the soil loss rates. In order to investigate the relationship between the landscape metrics for land cover and the watershed soil erosion, landscape metrics were calculated at the class level using FRAGSTAT software (version 4.2.1) for the years 2010 and 2020.

The most commonly used metrics are Number of Patches (NP), Patch Density (PD), Edge Density $(E D)$, Largest Patch Index (LPI), Percentage of Landscape (\%PLAND), Euclidean Nearest Neighbor Distance Area-Weighted Mean (ENN_AM), and Splitting Index (SPLIT) metrics. These selected metrics have been frequently used in previous studies in order to assess the links between land cover patterns and soil erosion [45,46].

- Number of Patches is the number of patches per unit area:

$$
N P=\sum_{i=1}^{n} P_{i}
$$

where $P_{i}$ is a patch of type $i$.

- Patch Density is the number of patches of a corresponding patch type (class) per unit area:

$$
P D=\left(\frac{n}{A}\right) \times 10,000 \times 100
$$

where $A$ is the area of a certain landscape type $\left(\mathrm{m}^{2}\right), n$ is the number of patches, and $10,000 \times 100$ is the number of patches per 100 hectares.

The higher the $P D$, the higher the degree of landscape fragmentation.

- Edge Density is the total length of all edge segments per hectare for the considered landscape:

$$
E D=\frac{E}{A} \times 10,000
$$

where $E$ is the total length of an edge in a landscape $(\mathrm{m})$ and $A$ is the total landscape area $\left(\mathrm{m}^{2}\right)$.

- $\quad$ Largest Patch Index is the percentage of the landscape in the largest patch (\%):

$$
L P I=\frac{\max \left(a_{i j}\right)}{A} \times 100
$$

where $a_{i j}$ is the area of patch $i j$ and $A$ is the total landscape area.

LPI is almost 0 when the largest patch in the landscape is too small; however, it equals 100 when the whole landscape consists of a single patch. In other words, the largest patch covers $100 \%$ of the landscape.

- Percentage of Landscape measures the extent percentage of each land cover class comprised of a particular patch type:

$$
\operatorname{PLAND}_{i}=\frac{\sum_{j=1}^{n} a_{i j}}{A} \times 100
$$

where $a_{i j}$ is the area of patch $j$ for the $i$ th land cover class and $A$ is the total landscape area. 
PLAND is almost zero when the corresponding land cover class is occasionally present in the landscape and approaches 100 when only a single patch of the corresponding land cover type still exists.

- Euclidean Nearest Neighbor Distance Area-Weighted Mean (ENN_AM) is the shortest straight-line distance $(\mathrm{m})$ between a focal patch and its nearest neighbor of the same class.

- $\quad$ Splitting Index is the number of patches obtained by subdividing the landscape into equal-sized patches based on the effective mesh size.

These metrics indicate the degrees of fragmentation for different land cover types and change images. According to these metrics, the multiple linear regression (MLR) approach was used in order to correlate soil erosion loss and landscape patterns.

\subsection{Morphometric Parameters Analysis}

Morphometric analysis is an efficient methodology for assessing the drainage network, stream gradient, and shape of basin. Morphometric parameters are categorized as basic, linear, relief, and shape parameters. The basic parameters mainly include the basin area, basin length, numbers and lengths of streams of each order, basin perimeter, and the bifurcation ratio derived from drainage networks and sub-basin polygons. All of these morphometric parameters were extracted from ALOS PALSAR DEM (12.5 m spatial resolution) for the study area. The other parameters (linear, shape, and relief) were extracted from the basic parameters. The equations used for the analysis of various morphometric parameters are shown in Table 7.

Table 7. Morphometric parameters.

\begin{tabular}{|c|c|c|c|c|c|}
\hline & \multicolumn{2}{|l|}{ Parameters } & \multicolumn{2}{|l|}{ Description/Equation } & Unit \\
\hline \multirow{6}{*}{$\begin{array}{c}\text { Basic } \\
\text { parameters }\end{array}$} & Area & (A) & \multicolumn{2}{|l|}{ Area of the watershed } & $\mathrm{km}^{2}$ \\
\hline & Basin perimeter & $(\mathrm{P})$ & \multicolumn{2}{|l|}{ The length of the watershed boundary } & $\mathrm{Km}$ \\
\hline & Basin length & $(\mathrm{Lb})$ & \multicolumn{2}{|c|}{ Distance between the watershed outlet and the farthest point on the watershed } & $\mathrm{Km}$ \\
\hline & Stream order & (u) & \multicolumn{2}{|l|}{ Hierarchical ranking } & Dimensionless \\
\hline & Number of stream & $(\mathrm{Nu})$ & \multicolumn{2}{|l|}{ Number of the stream segments of aparticular order } & \\
\hline & Stream length & $(\mathrm{Lu})$ & \multicolumn{2}{|l|}{ Total length of the stream segments of a particular order } & $\mathrm{Km}$ \\
\hline \multirow{5}{*}{$\begin{array}{c}\text { Linear } \\
\text { parameters }\end{array}$} & Bifrucation ratio & $(\mathrm{Rb})$ & $\begin{array}{l}\text { Ratio of the number of streams of a given order } u \text { to the number of } \\
\text { streams of higher order } u+1\end{array}$ & $R b=N_{u} / N_{u+1}$ & Dimensionless \\
\hline & Drainage density & (Dd) & $\begin{array}{c}\text { Ratio of the total length of the streams of all orders in the basin to } \\
\text { the area of the basin }\end{array}$ & $D d=L / A$ & $\mathrm{~km}^{-1}$ \\
\hline & Stream frequency & $(\mathrm{Fu})$ & Total number of streams of all orders per unit area of the basin & $F_{u}=\frac{\sum N_{u}}{A}$ & Streams. km ${ }^{-2}$ \\
\hline & Texture ratio & $(\mathrm{T})$ & $\begin{array}{l}\text { Ratio of the total number of streams of all orders to the perimeter } \\
\text { of the basin }\end{array}$ & $T=\frac{\sum N_{u}}{P}$ & $\mathrm{~km}^{-1}$ \\
\hline & Length of overland flow & (Lo) & $\begin{array}{l}\text { Length of the water flow over the ground before it combines with } \\
\text { the main stream }\end{array}$ & $L o=1 / 2 D d$ & $\mathrm{Km}$ \\
\hline \multirow{5}{*}{$\begin{array}{c}\text { Shape } \\
\text { parameters }\end{array}$} & Form factor & (Rf) & Ratio of basin area A to the square of length of the basin $\mathrm{Lb}$ & $R f=A / L b^{2}$ & M \\
\hline & Shape factor & (Bs) & Ratio of the square of the length of the basin $\mathrm{Lb}$ to the basin area A & $B s=L b^{2} / A$ & Dimensionless \\
\hline & Elongation ratio & $(\operatorname{Re})$ & $\begin{array}{l}\text { Ratio between the diameter of a circle with the same area as that of } \\
\text { the basin to the length of the basin }\end{array}$ & $\operatorname{Re}=1.128 \sqrt{A} / L b$ & Dimensionless \\
\hline & Compactness coefficient & $(\mathrm{Cc})$ & $\begin{array}{l}\text { Ratio between the basin perimeter and the area of a circle to the } \\
\text { same area of that basin }\end{array}$ & $C c=\frac{P}{2 \sqrt{\pi A}}$ & Dimensionless \\
\hline & Circularity ratio & (Rc) & $\begin{array}{c}\text { Ratio of the basin area to the area of circle having an equal } \\
\text { perimeter as the perimeter of the basin }\end{array}$ & $R c=4 \pi \frac{A}{P^{2}}$ & Dimensionless \\
\hline
\end{tabular}

The following flowchart (Figure 2) summarizes the framework of the paper. 


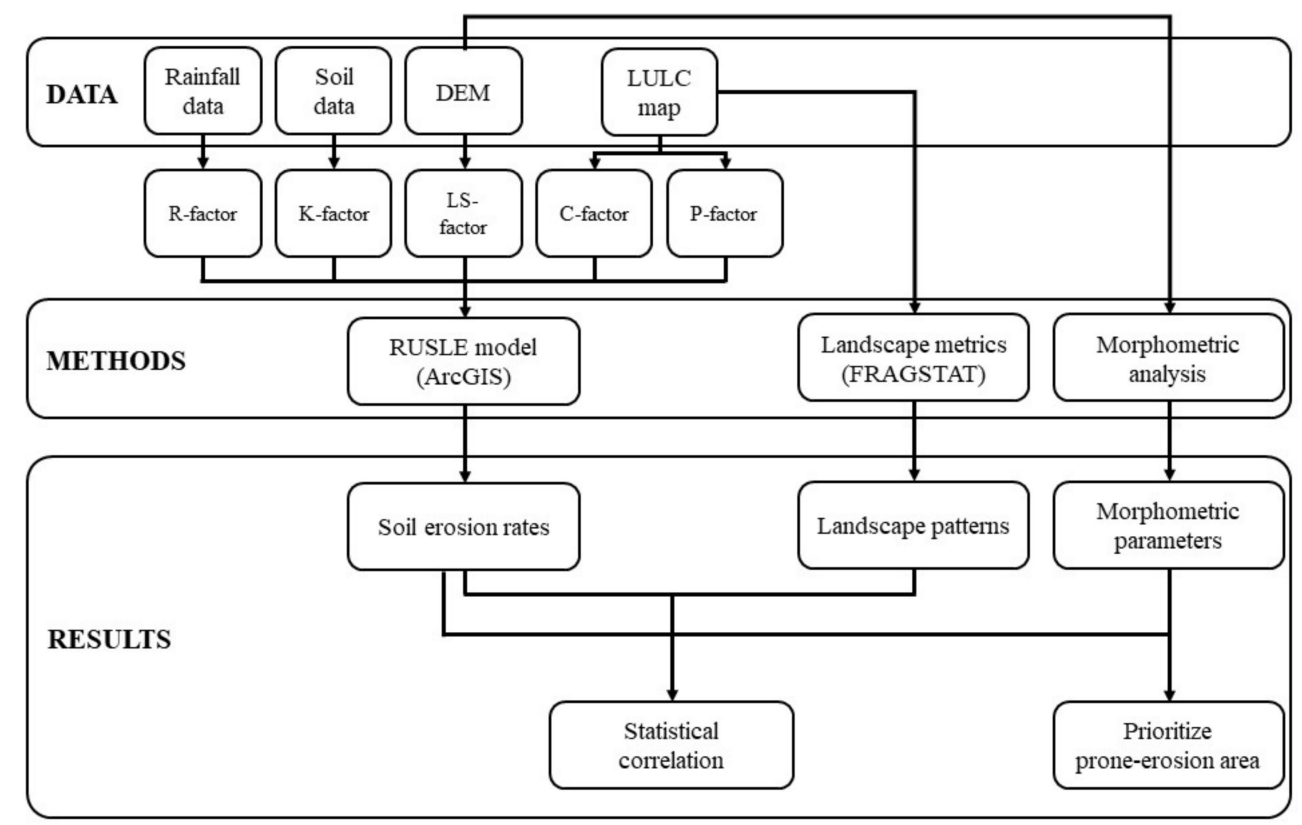

Figure 2. Flowchart of the research methodology.

\section{Results and Discussion}

\subsection{RUSLE Model}

In this study, the RUSLE model was integrated with GIS and remote sensing techniques to conduct cell-by-cell calculations of the mean annual soil loss rate ( $\mathrm{tha}^{-1}$ year $\left.^{-1}\right)$, and to identify and map soil erosion risk areas in the Paleochora region. Raster maps of each RUSLE parameter derived from different data source were produced and are discussed as follows.

\subsubsection{Rainfall Erosivity (R) Factor}

Satellite-Based Rainfall Erosivity (R) Factor

After applying the validation process, the MLR analysis revealed a significant relationship only between GPM and DEM, with $p$ values less than 0.05 for all the months; however, there was a weak correlation between GPM and NDVI, meaning all MLR models were significant and valid. Using the regression equations, the whole downscaling methodology was executed. An example of the results is shown in the following figure (Figure 3).

The RMSE values for the MLR method ranged from 0 to almost 56. Regarding bias, many values were negative, which can be explained by an underestimation of the precipitation. The coefficient of determination $\left(R^{2}\right)$ values ranged between 0.64 and 0.98 . These were higher for March, April, and December and lower for January, October, and November.

Once the downscaling process was accomplished, the R-factor was estimated according to Equation (2). The spatial pattern for the annual rainfall erosivity for Paleochora for 2020 at $10 \mathrm{~m}$ spatial resolution is shown in the following figure (Figure 4).

The map shows that the southern part of the study area (coastal area) has low $\mathrm{R}$ values (from approximately 108 to $500 \mathrm{MJ} \mathrm{mm} \mathrm{ha}{ }^{-1} \mathrm{~h}^{-1} \mathrm{y}^{-1}$ ); however, high R-values (from around 900 to $1200 \mathrm{MJ} \mathrm{mm} \mathrm{ha}{ }^{-1} \mathrm{~h}^{-1} \mathrm{y}^{-1}$ ) are estimated in the north-eastern part of the study area, which correspond to the highest altitude (corresponding to a high precipitation amount). In fact, the rainfall erosivity is higher in the area with high altitude and its adjoining areas, significantly enhancing the risk of soil erosion; thus, as the topography varies from steep to flat relief, the erosivity declines from 1286.11 to $108.41 \mathrm{MJ} \mathrm{mm} \mathrm{ha-1} \mathrm{h}^{-1} \mathrm{yr}^{-1}$, with a mean annual value of $501.8 \mathrm{MJ} \mathrm{mm} \mathrm{ha}{ }^{-1} \mathrm{~h}^{-1} \mathrm{yr}^{-1}$. 


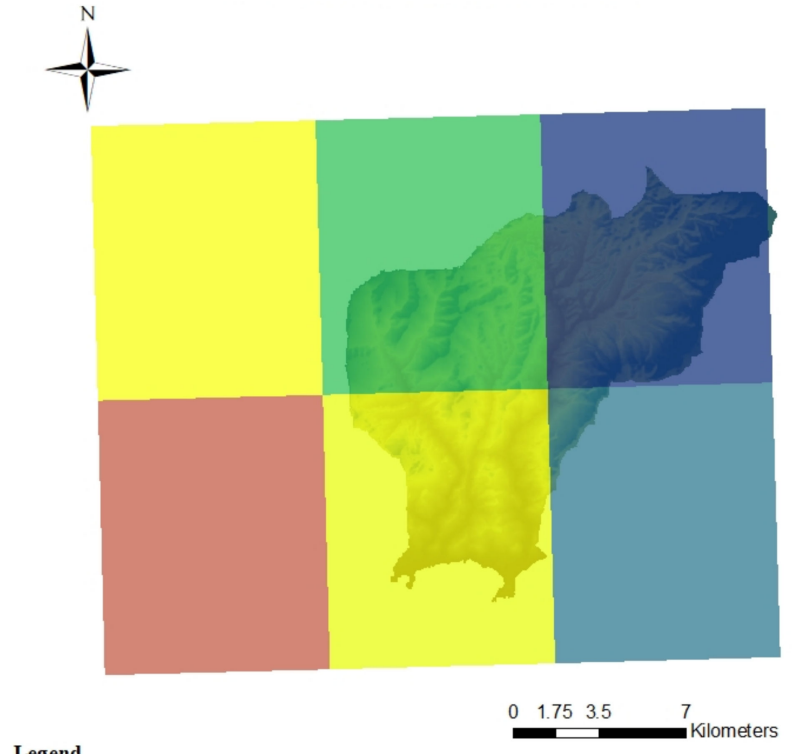

Legend

Precipitation $(\mathrm{mm})$

Value 51.6845

- 53.0545

(a)

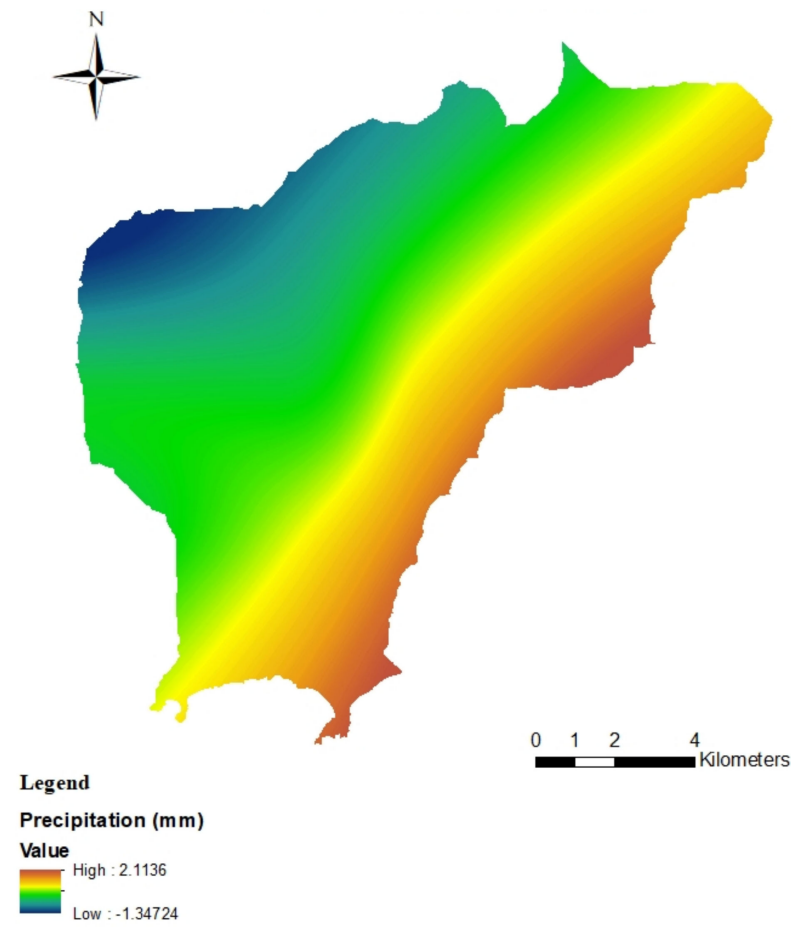

(c)

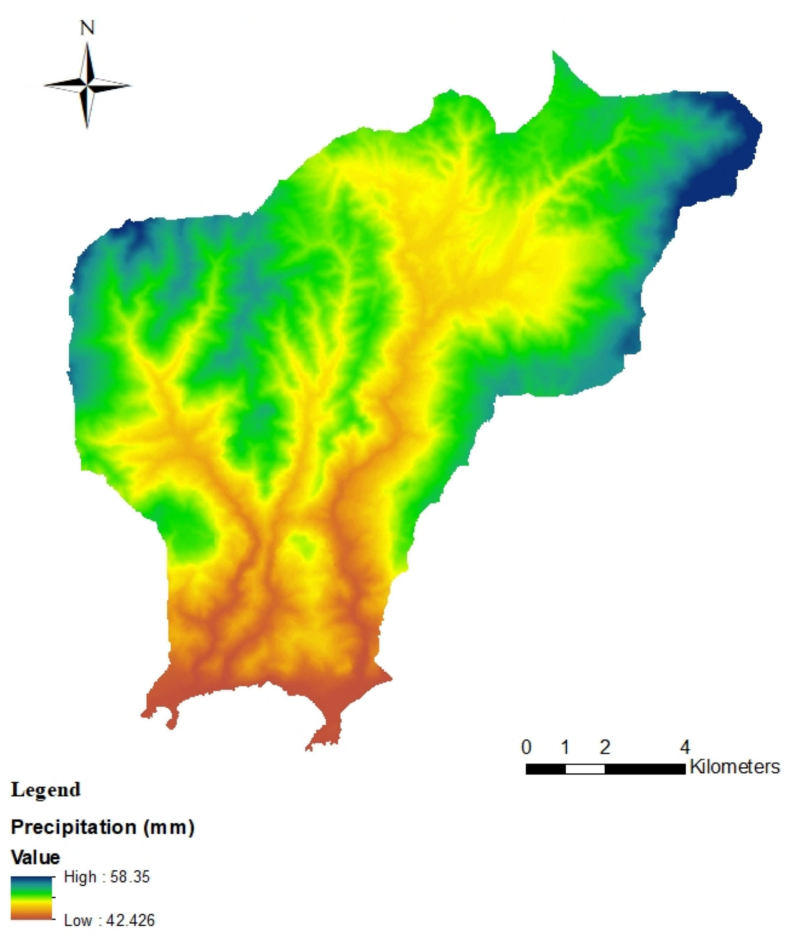

(b)

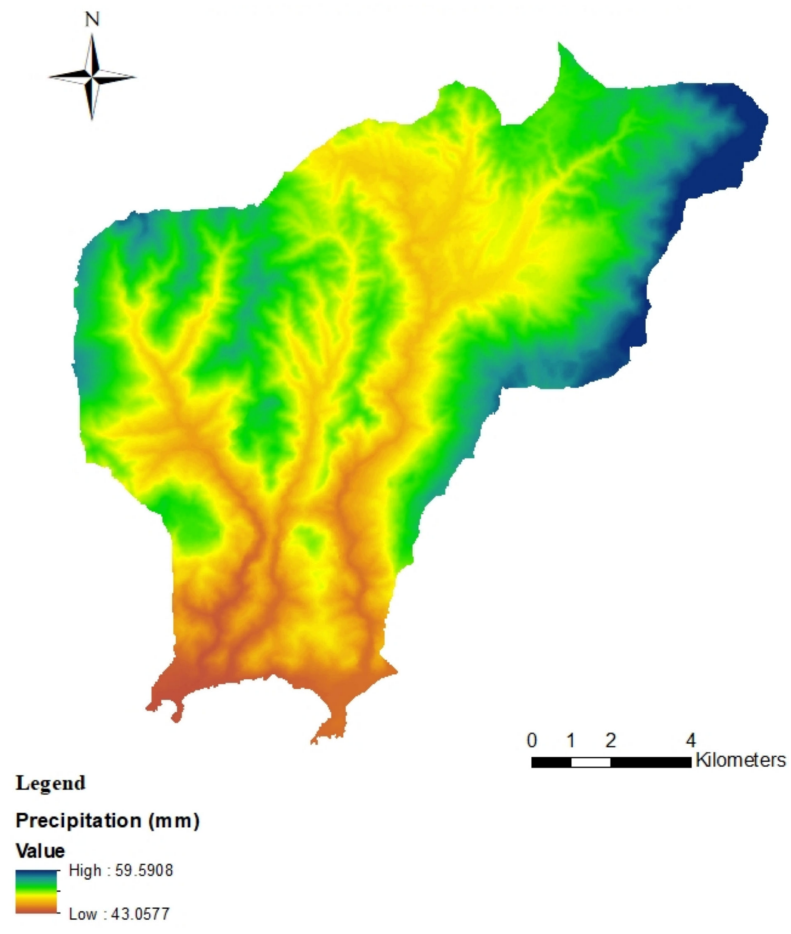

(d)

Figure 3. Regression-derived precipitation in the Paleochora region: (a) the IMERG precipitation values at $0.1^{\circ}$ resolution; (b) the estimated precipitation at $10 \mathrm{~m}$ resolution; (c) the interpolated residuals at $10 \mathrm{~m}$ resolution; (d) the downscaled precipitation at $10 \mathrm{~m}$ resolution. 


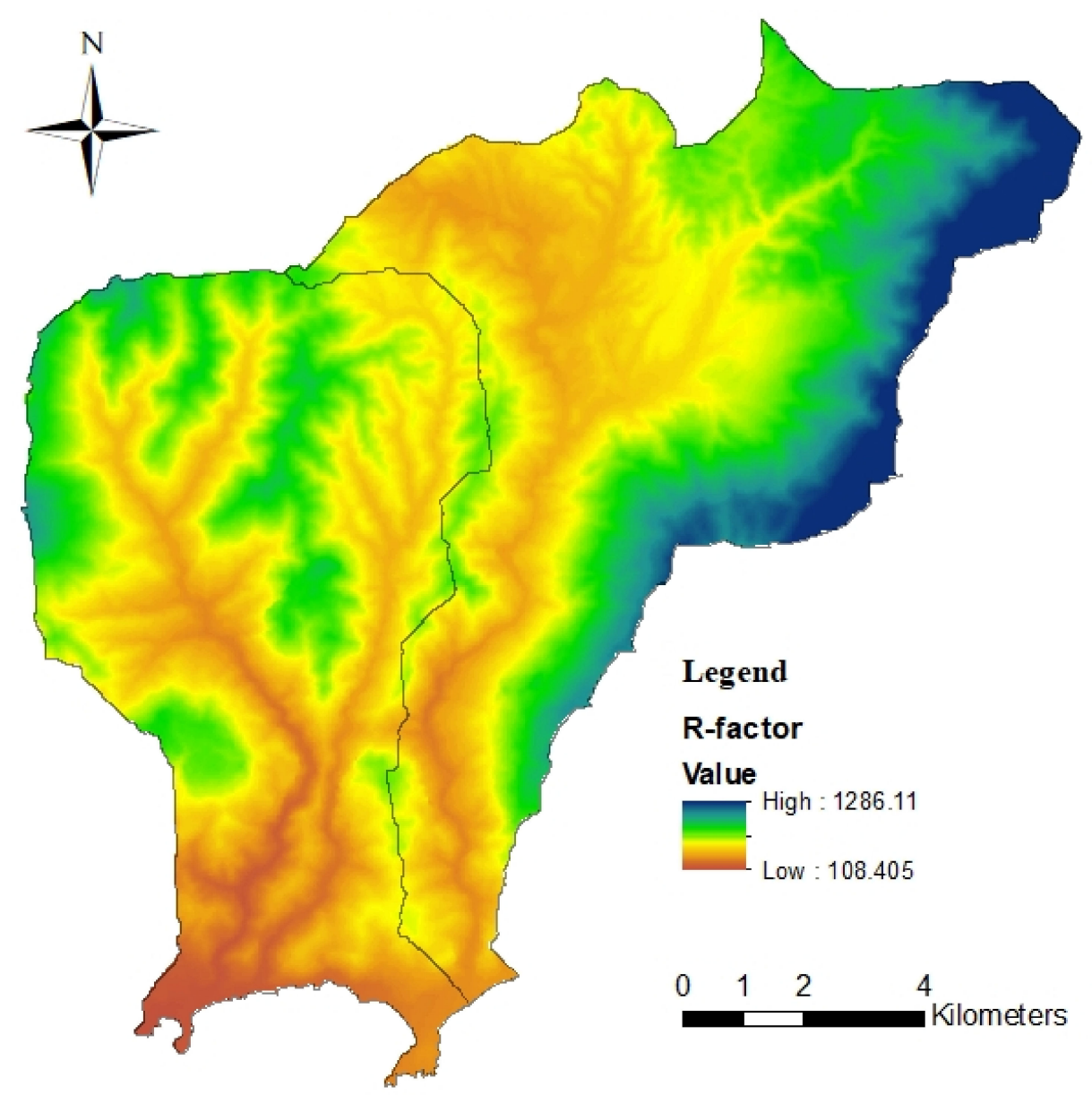

Figure 4. R-factor map calculated from downscaled IMERG daily data.

According to Panagos et al. [12], the mean annual R-factor for Crete was assessed to be $777 \mathrm{MJ} \mathrm{mm} \mathrm{ha}{ }^{-1} \mathrm{~h}^{-1} \mathrm{yr}^{-1}$ as applied in the $\mathrm{G} 2$ erosion model. In the same context, Panagos et al. [47] estimated the mean annual R-factor in Crete Island to be $846 \mathrm{MJ} \mathrm{mm} \mathrm{ha}{ }^{-1} \mathrm{~h}^{-1} \mathrm{yr}^{-1}$ and Grillakis et al. [28] found that the average R-factor for Crete island was estimated at $1818 \mathrm{MJ} \mathrm{mm} \mathrm{ha}^{-1} \mathrm{~h}^{-1}$ year $^{-1}$.

Compared to the studies by Panagos et al. $[47,48]$ in Europe and Greece, respectively, the spatial distribution pattern for the R-factor was in accordance with the proposed pattern maps; however, the R-factor values corresponding to Paleochora catchments were larger than the estimated R-factor values in this study.

\section{Ground-Based Rainfall Erosivity (R) Factor}

The R-factor values estimated from the 5 meteorological stations, which from the west to the east of Chania were denoted as Elos, Paleochora, Kandanos, Sebronas, and Samaria (Figure 5), varied between 131.25 and $958.857 \mathrm{MJ} \mathrm{mm} \mathrm{ha}{ }^{-1} \mathrm{~h}^{-1} \mathrm{y}^{-1}$ (Table 8), with a mean value of $432.879 \mathrm{MJ} \mathrm{mm} \mathrm{ha}{ }^{-1} \mathrm{~h}^{-1} \mathrm{y}^{-1}$ and with a relatively high standard deviation of 331.04 MJ mm ha ${ }^{-1} \mathrm{~h}^{-1} \mathrm{y}^{-1}$, which can be explained by the topography variations. 


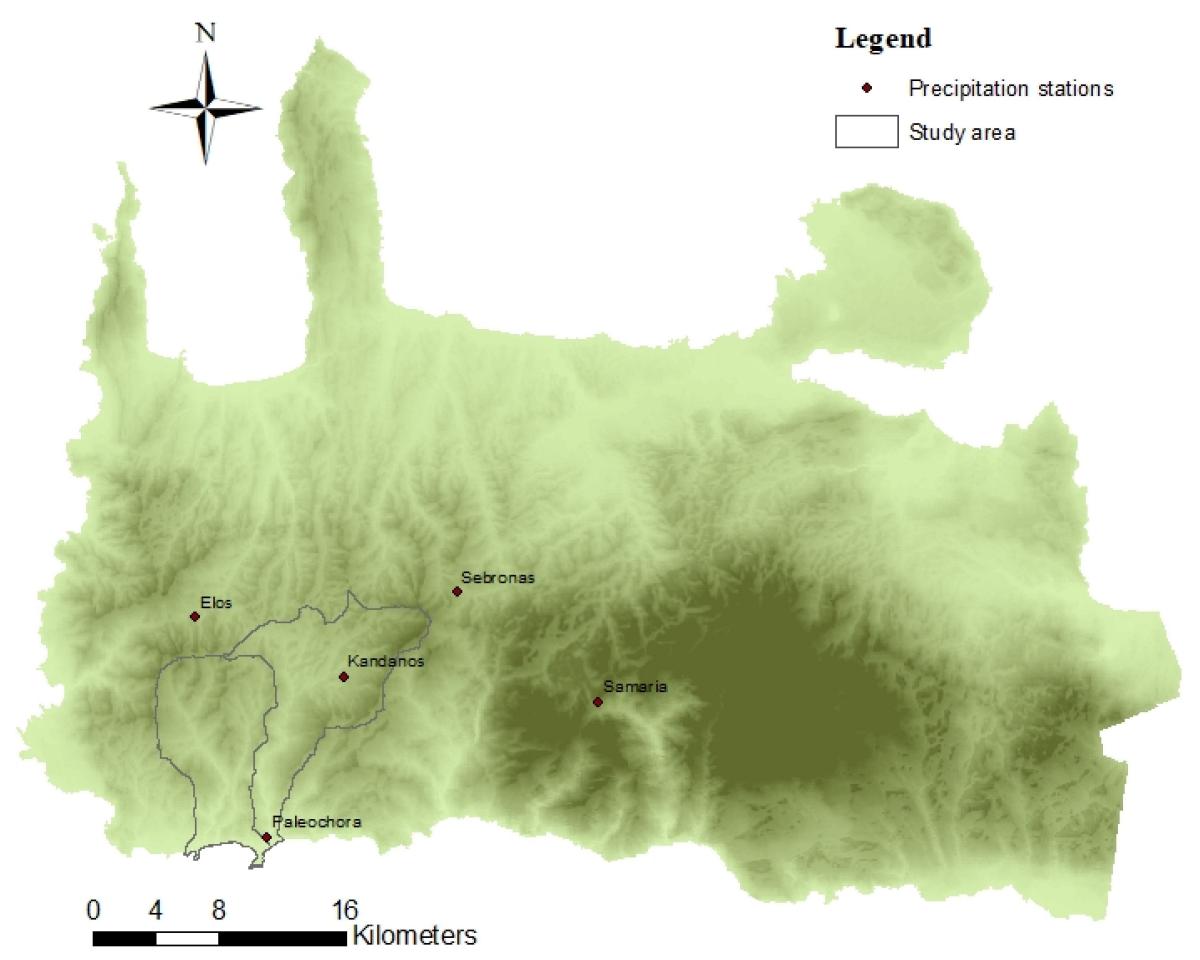

Figure 5. Shaded relief map of Chania (western part of Crete Island) showing the locations and spatial distribution of the meteorological (rain gauges) stations used in the current research.

Table 8. R-factor values for the precipitation stations.

\begin{tabular}{cc}
\hline Station Name & R-Factor $\mathbf{M J} \mathbf{~ m m} / \mathbf{h a ~ h} \mathbf{~ y r )}$ \\
\hline Elos & 288.429 \\
Paleochora & 545.625 \\
Kandanos & 240.214 \\
Sebronas & 131.25 \\
Samaria & 958.875 \\
\hline
\end{tabular}

The following map (Figure 6) shows the spatial pattern of the annual erosivity resulting from the extrapolation of the R-values. The R-factor values range from 240.248 to 545.536 MJ mm ha ${ }^{-1} \mathrm{~h}^{-1} \mathrm{y}^{-1}$, with a mean value of $347.734 \mathrm{MJ} \mathrm{mm} \mathrm{ha} \mathrm{m}^{-1} \mathrm{~h}^{-1} \mathrm{y}^{-1}$.

The $\mathrm{R}$-factor values derived from GPM data ranged between 108.41 MJ mm ha-1 $\mathrm{h}^{-1} \mathrm{yr}^{-1}$ to $1286.11 \mathrm{MJ} \mathrm{mm} \mathrm{ha}{ }^{-1} \mathrm{~h}^{-1} \mathrm{yr}^{-1}$; however, the $\mathrm{R}$-factor values derived from rain gauge data had larger minimum and smaller maximum values, ranging from $240.248 \mathrm{MJ} \mathrm{mm} \mathrm{ha-1} \mathrm{h}^{-1} \mathrm{yr}^{-1}$ to $545.536 \mathrm{MJ} \mathrm{mm} \mathrm{ha}{ }^{-1} \mathrm{~h}^{-1} \mathrm{yr}^{-1}$. The variation between the R-factor map derived from GPM data and in situ data can be explained by the difference in the data used to derive R-factor values (satellite-based data vs. ground-based data). Additionally, the GPM rainfall product has a tendency to overestimate low precipitation and underestimate intense precipitation [49]. Nevertheless, GPM proved to be a better alternative in estimating rainfall compared to rain gauge interpolation in areas where gauges are sparse. 


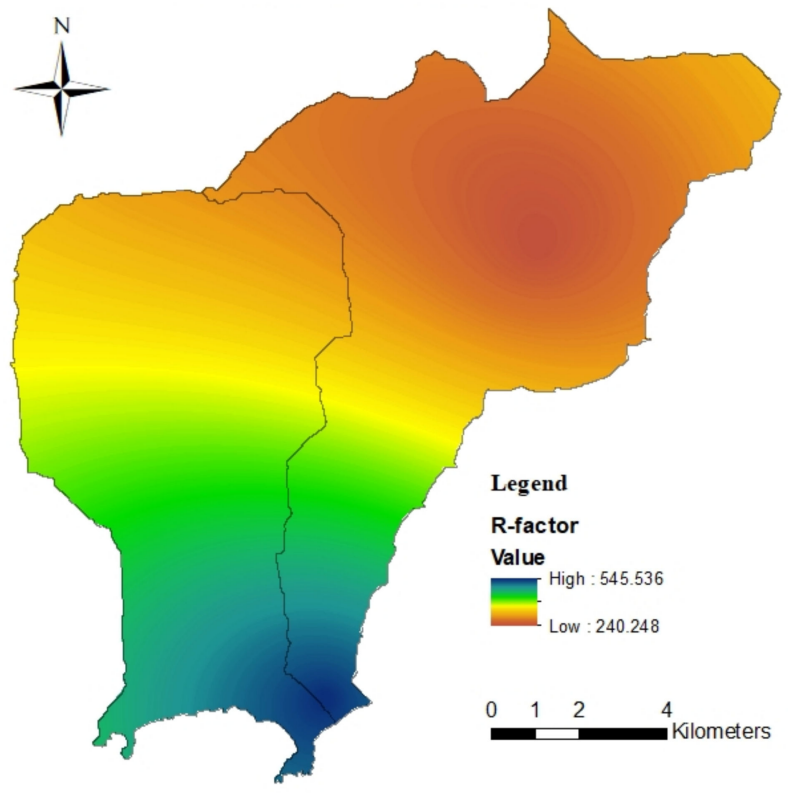

Figure 6. R-factor map derived from rain gauge data.

\subsubsection{Soil Erodibility (K) Factor}

The following map (Figure 7) represents the spatial distribution of the soil erodibility (K-factor).

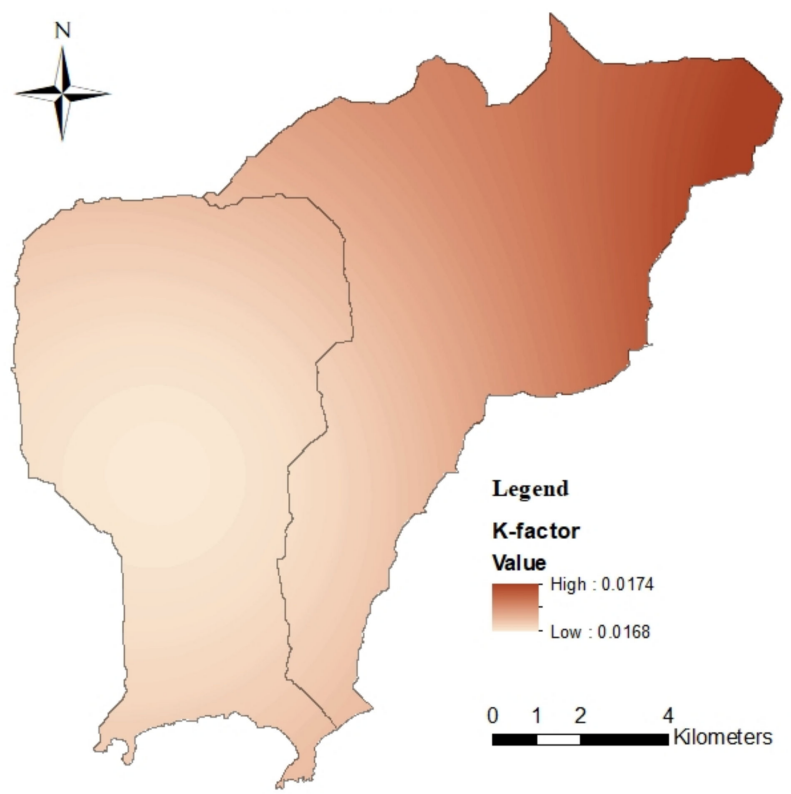

Figure 7. K-factor map.

The K-factor values ranged between 0.0168 and $0.0174 \mathrm{t} \mathrm{ha} \mathrm{h} \mathrm{ha}^{-1} \mathrm{MJ}^{-1} \mathrm{~mm}^{-1}$, with a mean value of almost $0.017 \mathrm{tha} \mathrm{h} \mathrm{ha}{ }^{-1} \mathrm{MJ}^{-1} \mathrm{~mm}^{-1}$ and a standard deviation of 0.00015 . $\mathrm{K}$-values tended to increase from southwest to northeast. Commonly, soils high in clay have low K-values at about 0.05 to $0.15 \mathrm{t}$ ha h ha ${ }^{-1} \mathrm{MJ}^{-1} \mathrm{~mm}^{-1}$. This soil category is resistant to detachment.

In addition, organic matter reduces erodibility because it reduces the susceptibility of the soil to detachment and increases infiltration, which reduce runoff and erosion.

At the European level, the mean K-factor value was estimated to be $0.032 \mathrm{tha} \mathrm{h} \mathrm{ha}^{-1}$ $\mathrm{MJ}^{-1} \mathrm{~mm}^{-1}$ [15]. At the country level, according to the study by Panagos et al. [20], the mean value of $\mathrm{K}$-factor for Greece was $0.0298 \mathrm{t}$ ha h ha ${ }^{-1} \mathrm{MJ}^{-1} \mathrm{~mm}^{-1}$. At the catchment 
level, K-factor values ranged between 0.009 and around $0.04 \mathrm{tha} \mathrm{h} \mathrm{ha}{ }^{-1} \mathrm{MJ}^{-1} \mathrm{~mm}^{-1}$ in the northern central and northwestern parts of Chania, Crete [3,50].

\subsubsection{Slope Length-Steepness (LS) Factor}

The derived LS-factor map is shown in the following figure (Figure 8).

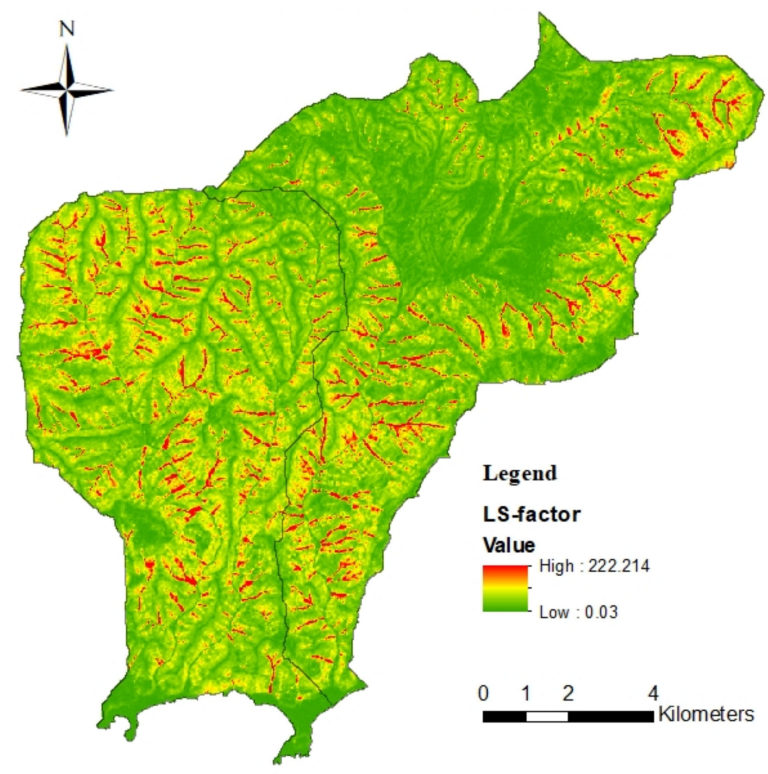

Figure 8. LS-factor map.

As the slope gradient is the main component affecting the LS-factor, flat areas have low LS-values, while areas with steep slope gradients have higher LS-values, which render these areas extremely susceptible to erosion. Additionally, LS-values are also greater along the flow path and increase abruptly at areas of flow concentration. The mean LS-factor value for the whole study area was 8.72, with a range of 0 to 222 .

Both catchments were characterized by relatively high LS-factor values, consistent with the high elevation values (around $1300 \mathrm{~m}$ ) and the greatest extent of the catchments (around $148 \mathrm{~km}^{2}$ ). In the northwestern part of Chania, Kouli et al. [3] found similar K-values for catchments with similar characteristics.

\subsubsection{Cover Management (C) Factor}

This factor can be assessed in different ways depending on the availability of the data. Remote-sensing-based methods such as land use/land cover (LULC) classification and spectral indices such as the Normalized Difference Vegetation Index (NDVI) and its derivation the Fractional Vegetation Cover (FVC) have been proven to be informative in deriving the C-factor.

Regardless of the classification algorithm, the resulting classified images showed spectral confusion in some thematic classes, such as for young olive groves (Corine class no. 223) with Sclerophyllous vegetation (Corine class no. 323) and for Sclerophyllous vegetation (Corine class no. 323) with broadleaf forest areas (Corine class no. 311).

The RF classifier showed the highest overall accuracy ( $86 \%)$ and Kappa statistics $(\sim 78 \%)$ among the classifiers. Consequently, all of the selected Sentinel-2 images were classified separately, since every image was acquired on a different date using the RF classifier. The final land cover map (Figure 9) showed an overall accuracy of about $95 \%$ and Kappa statistics of about $93 \%$. The Kappa coefficient values ranged between $81 \%$ and $100 \%$, means there was an almost perfect agreement between the classification and the reference data. 


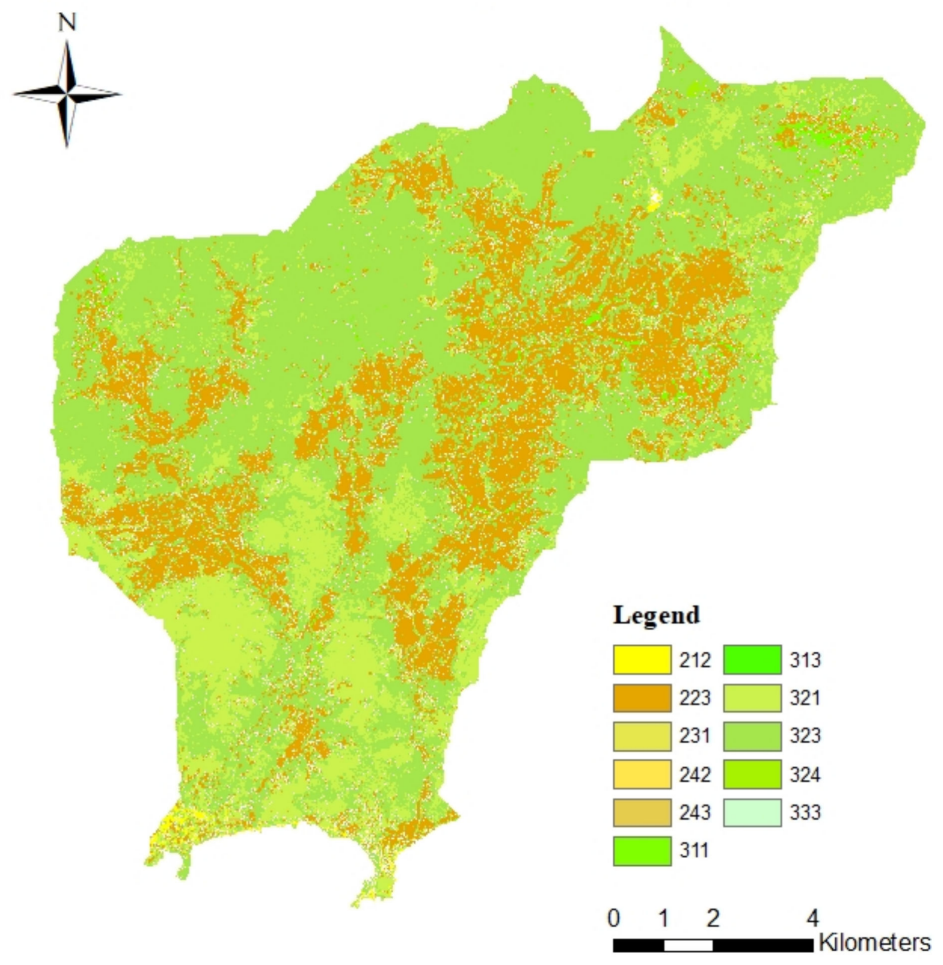

Figure 9. Classified LULC map for Paleochora (2020).

After determining the LULC classes from the remotely sensed data, corresponding $\mathrm{C}$-factor values were assigned from literature. The C-factor map derived from the land cover classification (Figure 10) showed that forested areas had the lowest $C$-factor values, while agriculture areas had higher values.

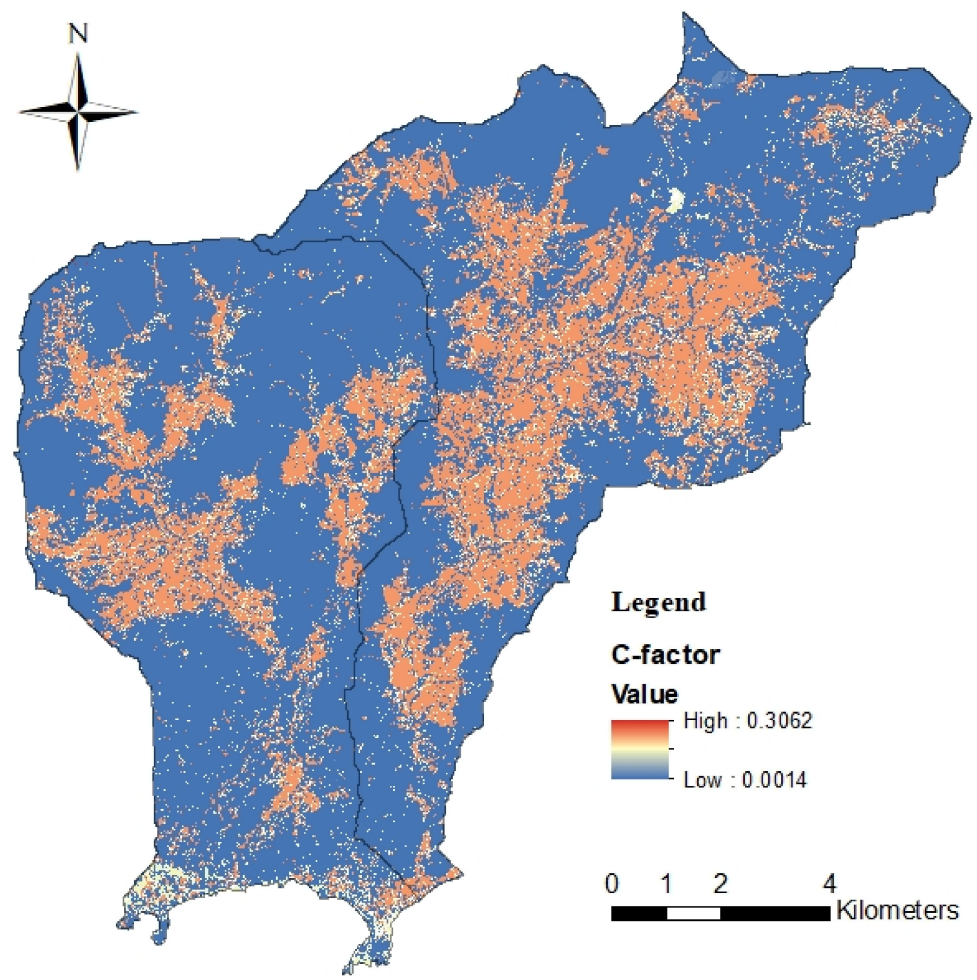

Figure 10. C(literature)-factor map. 
Regarding the NDVI, several empirical relations were established to correlate NDVI values to C-factor values. Commonly, NDVI is directly correlated to the C-factor by an exponential regression [36] or a linear regression [37]. C(vk)-factor and $C(\mathrm{r})$-factor maps (Figures 11 and 12, respectively) derived from the NDVI index seemed to have approximately the same trend for the value distribution. These maps showed almost similar values for forested areas (almost zero) and agricultural areas (ranging between $\sim 0.15$ and $\sim 0.2$ ) in comparison to the C-factor map derived from supervised classification; however, $\mathrm{C}(\mathrm{vk})$-factor and $\mathrm{C}(\mathrm{r})$-factor values were incredibly high in some areas, such as the "natural grassland" areas. As such, $\mathrm{C}(\mathrm{vk})$-values and $\mathrm{C}(\mathrm{r})$-values for those areas were replaced by $\mathrm{C}_{\mathrm{LIT}}$-values from the literature, as recommended by Rubianca et al. [25].

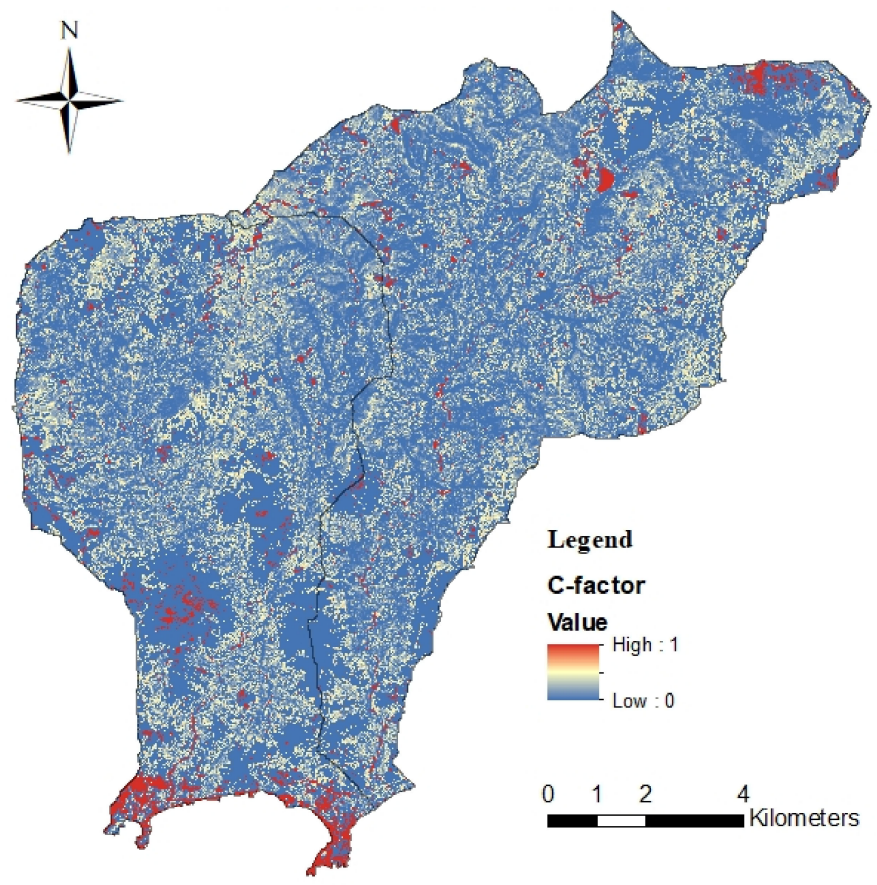

Figure 11. $C(v k)$-factor map.

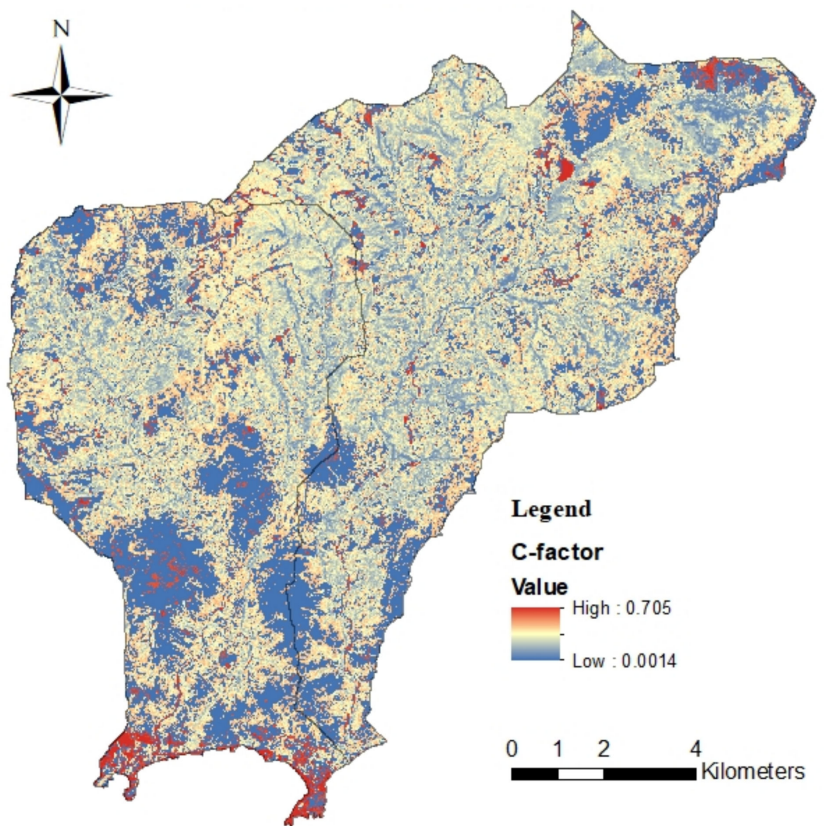

Figure 12. C(r)-factor map. 
Similar to the C-factor map derived from the NDVI, the C(FVC)-values assigned to the "natural grassland" were overestimated; thus, these values were substituted for C-values from the literature (Figure 13).

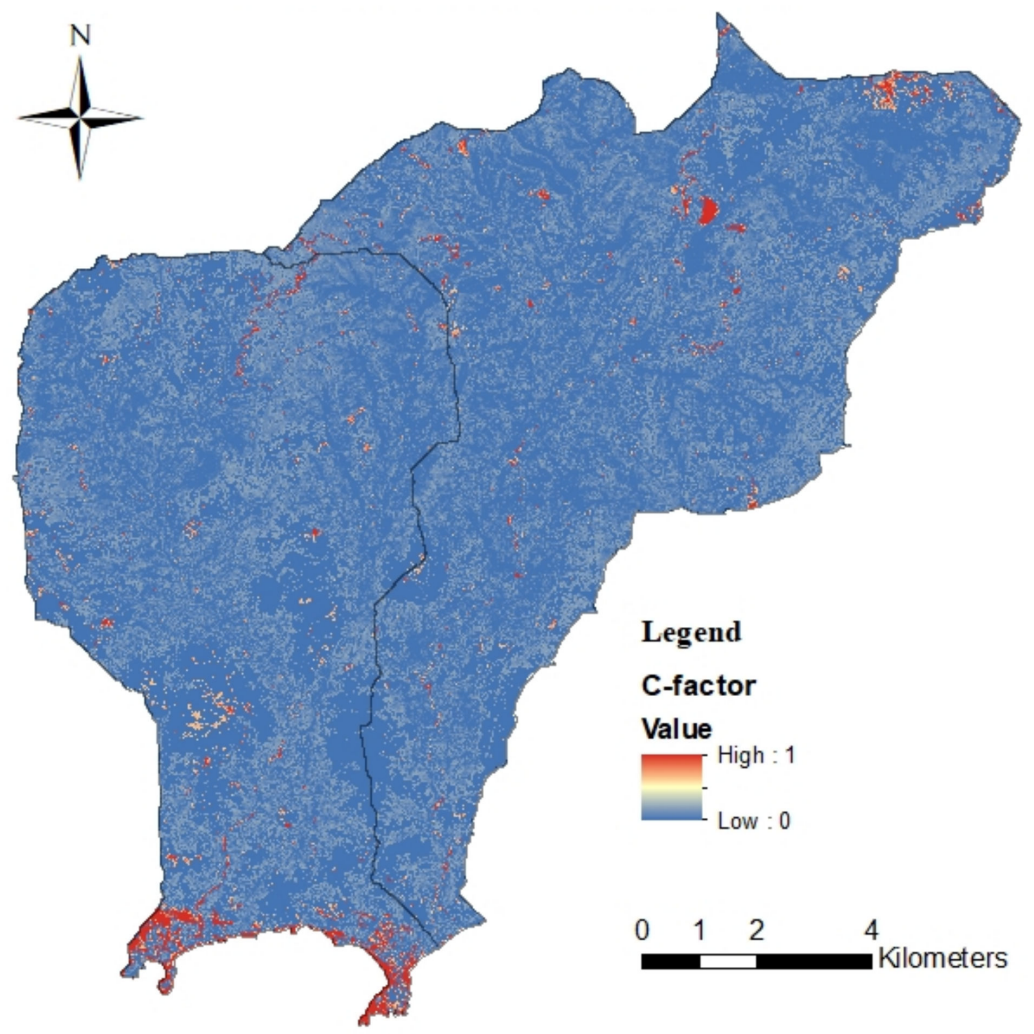

Figure 13. C(FVC)-factor map.

The comparison of the different methods (classification and NDVI) used to obtain $\mathrm{C}$-factor showed that $\mathrm{C}$-values derived from NDVI were overestimated in comparison to $\mathrm{C}$-values from the literature; however, $\mathrm{C}$-values derived from FVC seemed to be more reliable compared to $\mathrm{C}$-values from the literature.

Another problem with NDVI and its sub-product (FVC) is the high values assigned to the "natural grassland". This can be explained by the fact that they are considered as moderate vegetation so their NDVI is quite low ( 0.2 to $\sim 0.3)$. Consequently, they will have high C-values. This type of land cover has a significant impact on the $\mathrm{C}$-factor as well. The effect of grassland on soil conservation is much better than that of agricultural land, as confirmed by $\mathrm{C}$-values from the literature.

On the other hand, the rescaled C-factor equation was originally proposed for tropical climatic conditions and FVC equations were originally suggested for Chinese catchments. Since these zone have different climatic conditions and land covers to the Mediterranean study area, this could also influence the results.

\subsubsection{Support Practices (P) Factor}

The contour sub-factor $\left(P_{c f}\right)$ was estimated based on the slope derived from the DEM, for which the mean $P_{c f}$ was 0.88 . The stone walls $\left(P_{s w}\right)$ and the grass margin $\left(P_{g m}\right)$ subfactors were estimated based on the interpolated stone walls and grass margin dataset, for which the mean $P_{s w}$ was 0.67 and the mean $P_{g m}$ was 0.85 .

The mean P-factor value, combining the 3 sub-factors, was estimated to be 0.82 . The derived P-factor map (Figure 14) showed that the areas where erosion management practices were conducted were specifically in Corine-cultivated land. The P-factor values ranged between 0.22 and 0.57 , with lower values indicating that support practice management 
reduced erosion; however, the P-factor value was considered as 1 (no practices) for areas covered by forest.

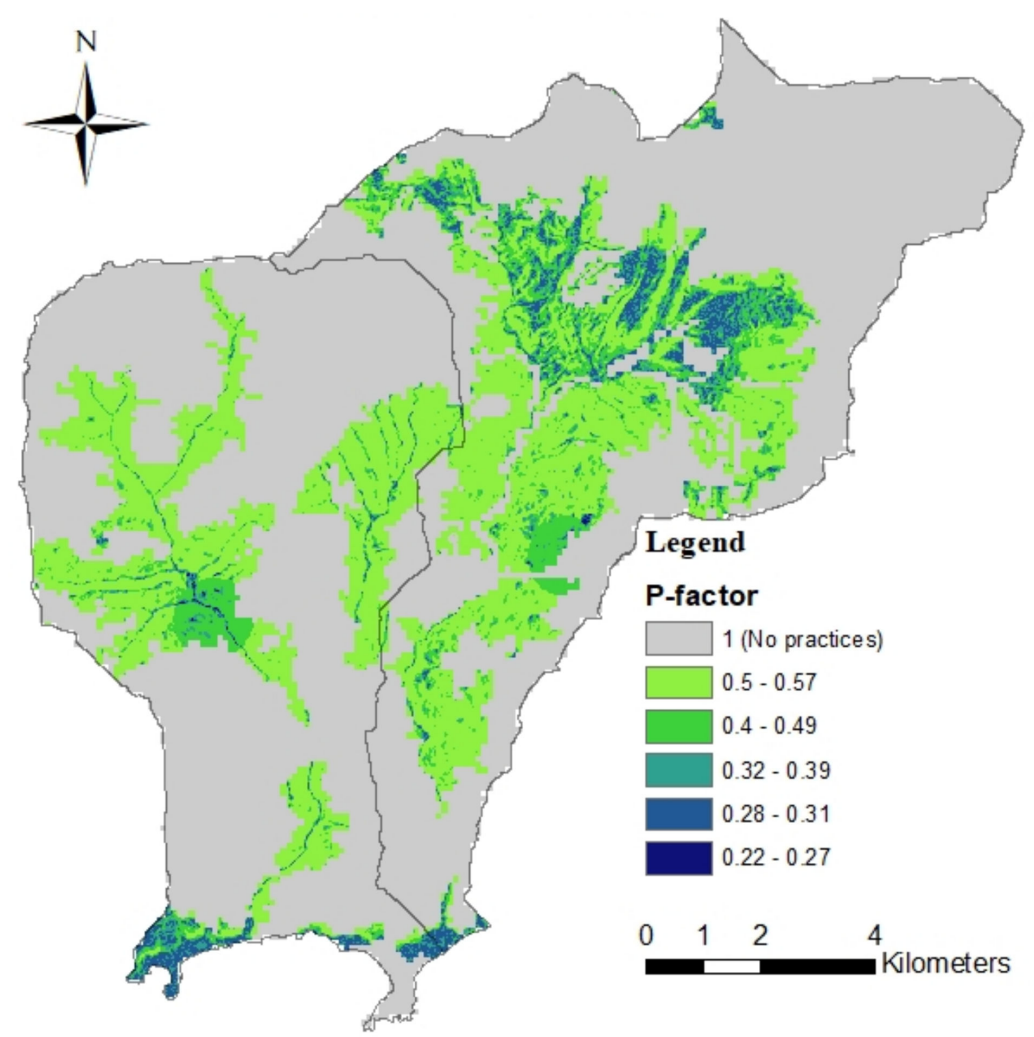

Figure 14. P-factor values for Paleochora.

In several studies, because of a lack of data, the P-factor was set to 1, yet in several studies the P-factor was estimated using image classification or LUCAS data $[4,19]$. A study conducted at the European level showed that in Greece the mean P-factor values is about 0.95 .

\subsubsection{RUSLE Model}

Soil loss values were calculated by overlaying five grid rasters (a grid raster representing $\mathrm{R}$-factor values, a grid raster representing $\mathrm{K}$-factor values, a grid raster representing LS-factor values, a grid raster representing $\mathrm{C}$-factor values, and a grid raster representing P-factor values).

The final maps produced show the spatial distribution of annual soil loss within the study area at $10 \mathrm{~m}$ pixel resolution according to each scenario:

- Scenario 1: A soil loss map was produced with R-factor values derived from satellite data and C-factor values assigned from literature data (Figure 15);

- $\quad$ Scenario 2 and 3: Two soil loss maps were produced with R-factor values derived from satellite data and C-factor values derived from NDVI (exponential (NDVI-vk) and linear (NDVI-r) equation) data (Figures 16 and 17, respectively);

- Scenario 4: A soil loss map was produced with R-factor values derived from satellite data and C-factor values derived from FVC data (Figure 18). 


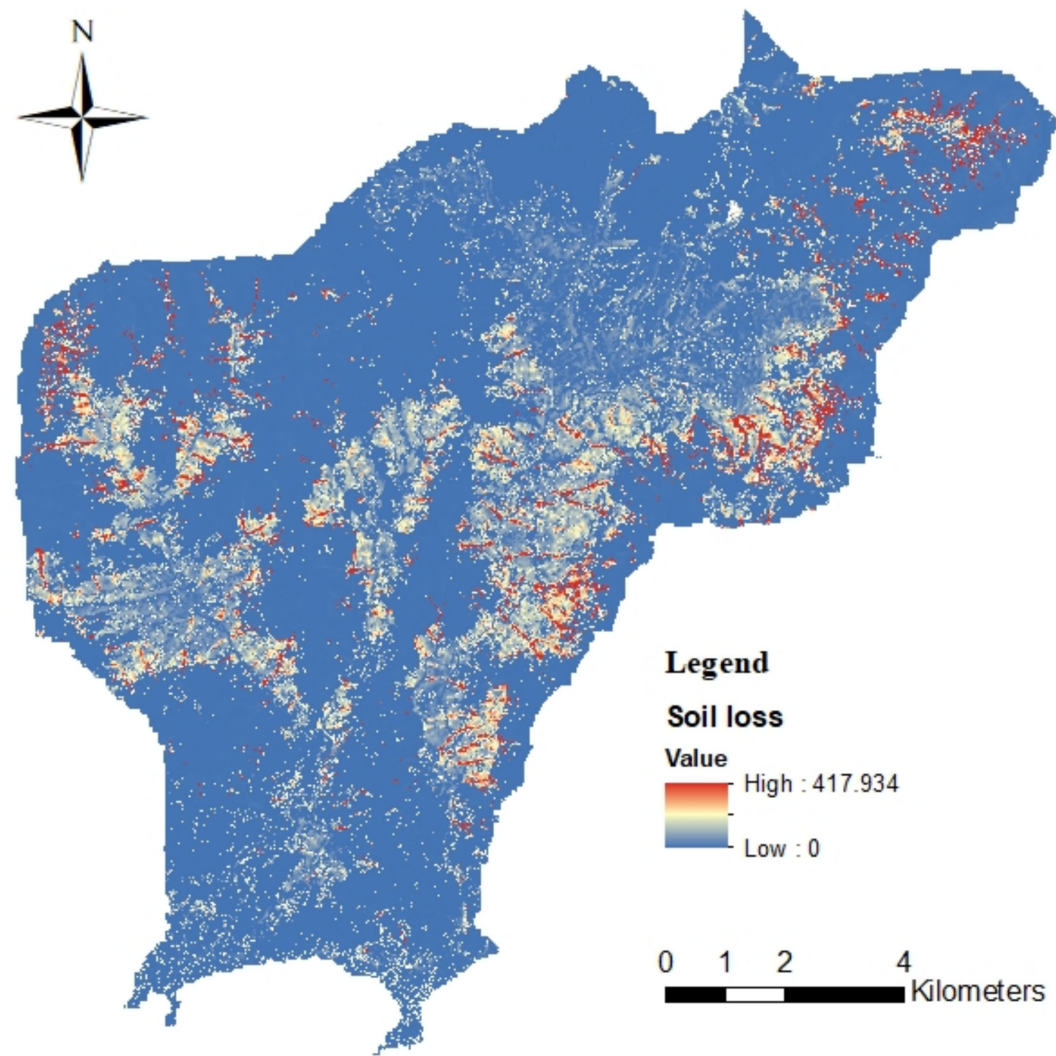

Figure 15. Soil loss map produced using R from the Global Precipitation Measurements (GPM) and $\mathrm{C}$ from the literature data.

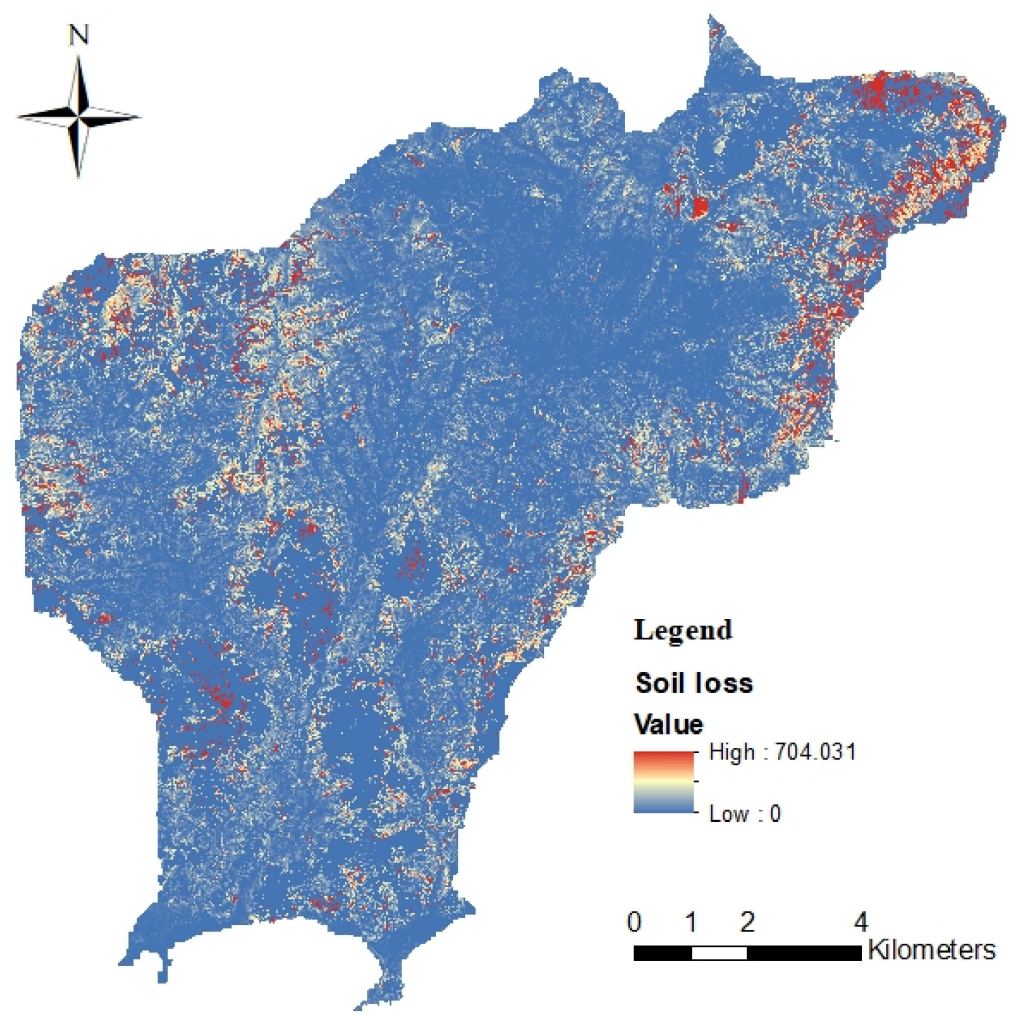

Figure 16. Soil loss map produced using R from the Global Precipitation Measurements (GPM) and $\mathrm{C}$ from $N D V I(\mathrm{vk})$ data. 


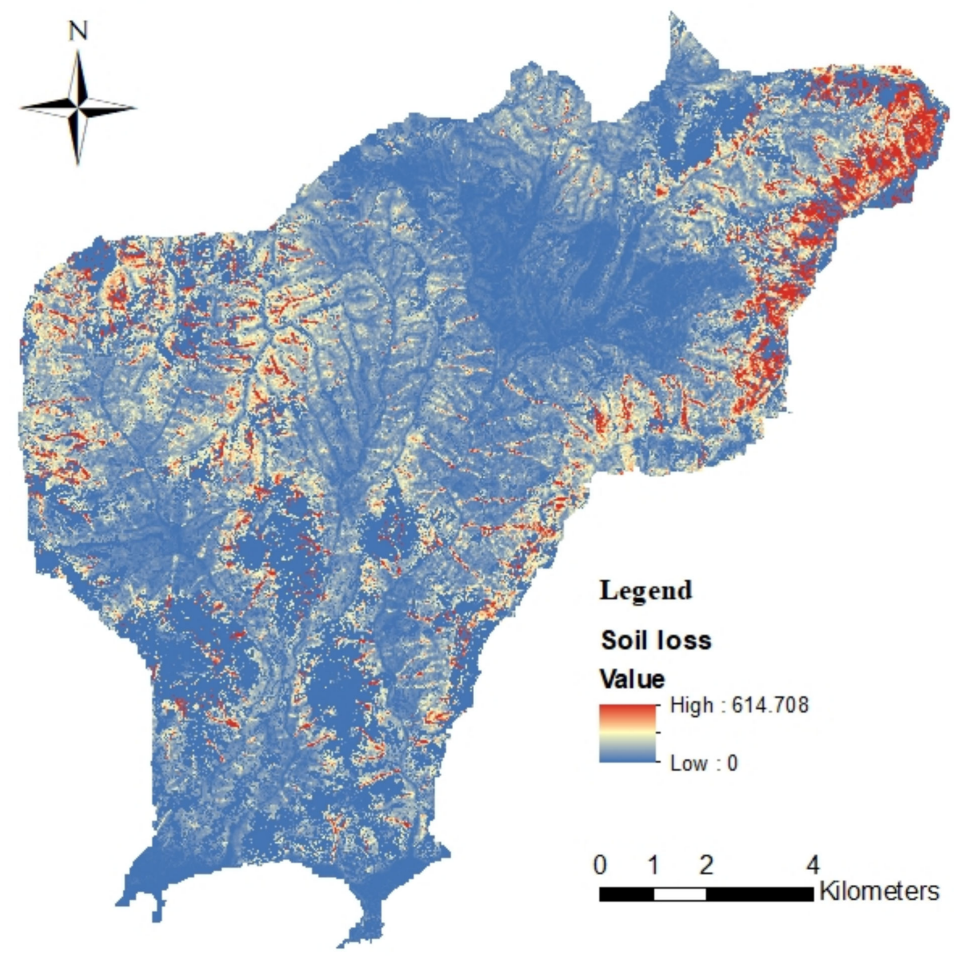

Figure 17. Soil loss map produced using R from the Global Precipitation Measurements (GPM) and C from NDVI(r) data.

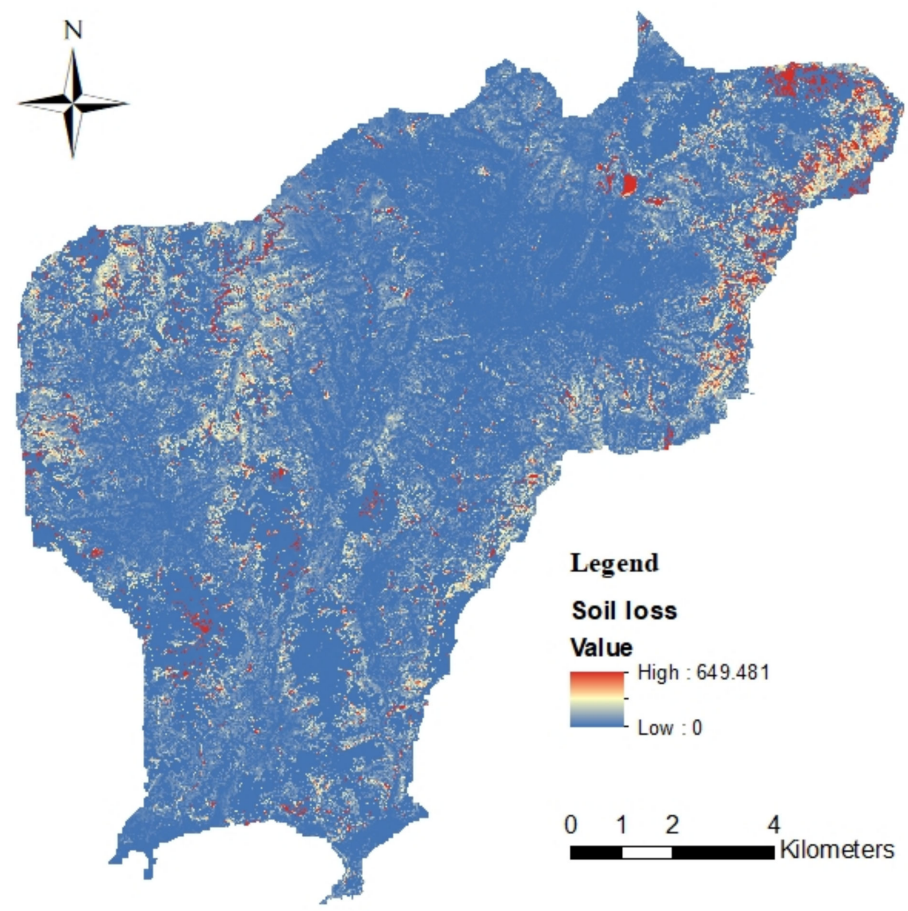

Figure 18. Soil loss map produced using R from the Global Precipitation Measurements (GPM) and C from NDVI-derived Fractional Vegetation Cover(FVC) data.

According to scenarios 1, 2, 3, and 4, the maximum estimated soil losses were 417, 704, 614 , and $649 \mathrm{tha}^{-1}$ year ${ }^{-1}$, with mean values of $2.59,4.63,10.01$, and $2.41 \mathrm{t} \mathrm{ha}^{-1}$ year $^{-1}$, respectively.

The results for the RUSLE model were in relative agreement with previous studies. In fact, at the European level, the mean annual soil loss rate is about $2.46 \mathrm{t} \mathrm{ha}^{-1}$ [51]. 
According to the work by Panagos et al. [12], the mean annual soil loss rate in Crete was found to be $8.123 \mathrm{t} \mathrm{ha}^{-1} \mathrm{yr}^{-1}$. A soil erosion map of the northern central part of Chania, Crete, showed that soil erosion in cultivated areas was commonly greater than soil erosion in uncultivated areas, with a mean annual erosion rate of $4.85 \mathrm{tha}^{-1} \mathrm{yr}^{-1}$ [50]; however, the variations in the mean values can be explained be the different methods used in extracting the factors and the assessment scale.

The spatial distribution of the soil erosion rates was evaluated for different land cover classes, which were mainly agricultural, forest, natural grassland and pasture, shrubland, and sparsely vegetated areas (Table 9 and Figure 19).

Table 9. Soil erosion rates in terms of land cover.

\begin{tabular}{ccccc}
\hline \multirow{2}{*}{ Land Cover Class } & \multicolumn{3}{c}{ Mean Annual Soil Loss (t ha ${ }^{-\mathbf{1}}$ Year $^{-\mathbf{1}}$ ) } \\
\cline { 2 - 5 } & Scenario 1 & Scenario 2 & Scenario 3 & Scenario 4 \\
\hline Agricultural areas & 5.882 & 5.642 & 6.873 & 5.253 \\
Forest & 0.145 & 1.452 & 8.932 & 0.835 \\
Natural grassland and pasture & 3.064 & 5.241 & 5.809 & 2.896 \\
Shrubland & 0.912 & 4.950 & 11.381 & 2.491 \\
Sparsely vegetated areas & 37.927 & 4.693 & 4.142 & 0.864 \\
\hline
\end{tabular}

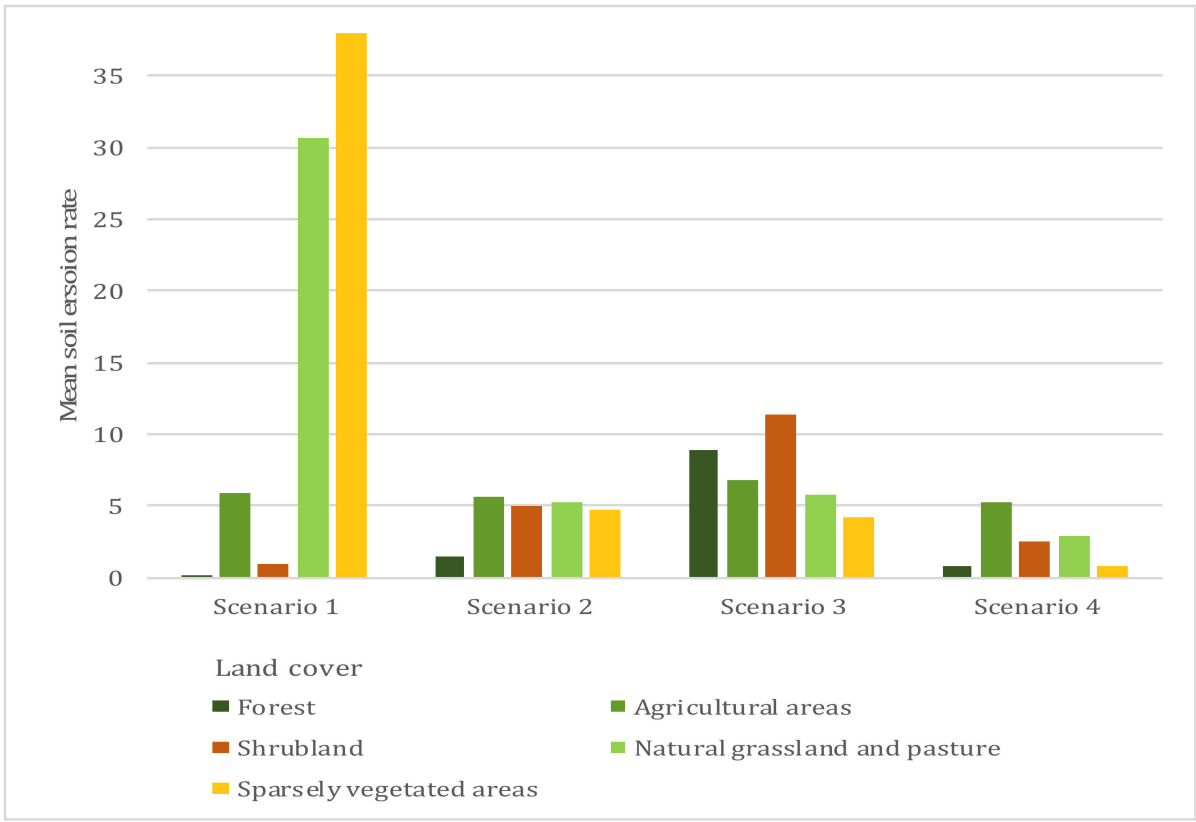

Figure 19. Bar diagram showing soil erosion rates in terms of land cover.

According to scenario 1, the mean erosion rate for sparsely vegetated areas was the highest, followed by agricultural, natural grassland and pasture, shrubland, and forest areas.

According to scenario 2, the mean erosion rate for agricultural areas was the highest, followed by natural grassland and pasture, shrubland, sparsely vegetated, and forest areas.

According to scenario 3, the mean erosion rate for sparsely vegetated areas was the lowest and higher values were assigned to natural grassland and pasture, agricultural areas, forest, and shrubland areas.

According to scenario 4 , the mean erosion rates for sparsely vegetated and forest areas were the lowest and higher values were assigned to shrubland, natural grassland and pasture, and agricultural areas.

In their study, Panagos et al. [12] estimated the spatial distribution of soil erosion rates per land cover and land use class based on the Corine Land Cover dataset. According to 
their assessment, the mean annual soil loss rate was found to be $8.123 \mathrm{t} \mathrm{ha}^{-1}$. The mean erosion rate for sparsely vegetated areas was the highest, followed by natural grassland and pasture, shrubland, agricultural areas, and forest areas.

Consequently, both scenario 3 and scenario 4 , which presented low values for sparsely vegetated areas, were excluded.

A cell-by-cell analysis of the soil loss map showed that the highest soil loss values were positively correlated with the steepest slopes. This finding was confirmed with reference to the study by Kouli et al. [3] in Chania, Crete; however, in this study, the correlation was higher for scenario 2 than scenario 1, meaning scenario 2 was considered to provide the most reliable results for soil loss estimation.

Soil loss values were calculated by overlaying five grid rasters (a grid raster representing $\mathrm{R}$-factor values estimated from rain gauge data, a grid raster representing $\mathrm{K}$-factor values, a grid raster representing LS-factor values, a grid raster representing C-factor values, and a grid raster representing P-factor values).

The final maps produced to show the spatial distribution of annual soil loss within the study area at $10 \mathrm{~m}$ pixel resolution were as follows:

- Scenario 5: A soil loss map was produced with R-factor values derived from in situ data and C-factor values assigned from literature data (Figure 20);

- Scenario 6: A soil loss map was produced with R-factor values derived from in situ data and C-factor values derived from NDVI (exponential (NDVI-vk)) data (Figure 21).

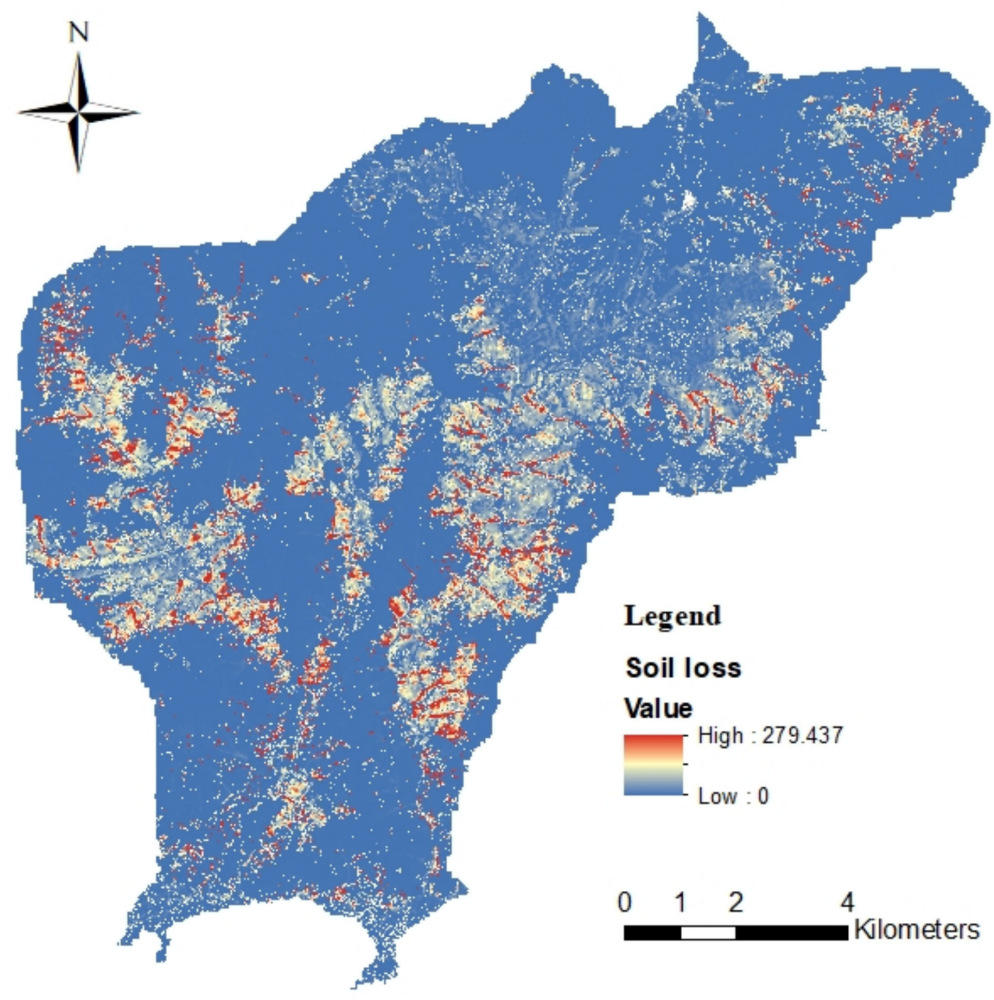

Figure 20. Soil loss map with R-factor values derived from in situ data and C-factor values derived from literature data. 


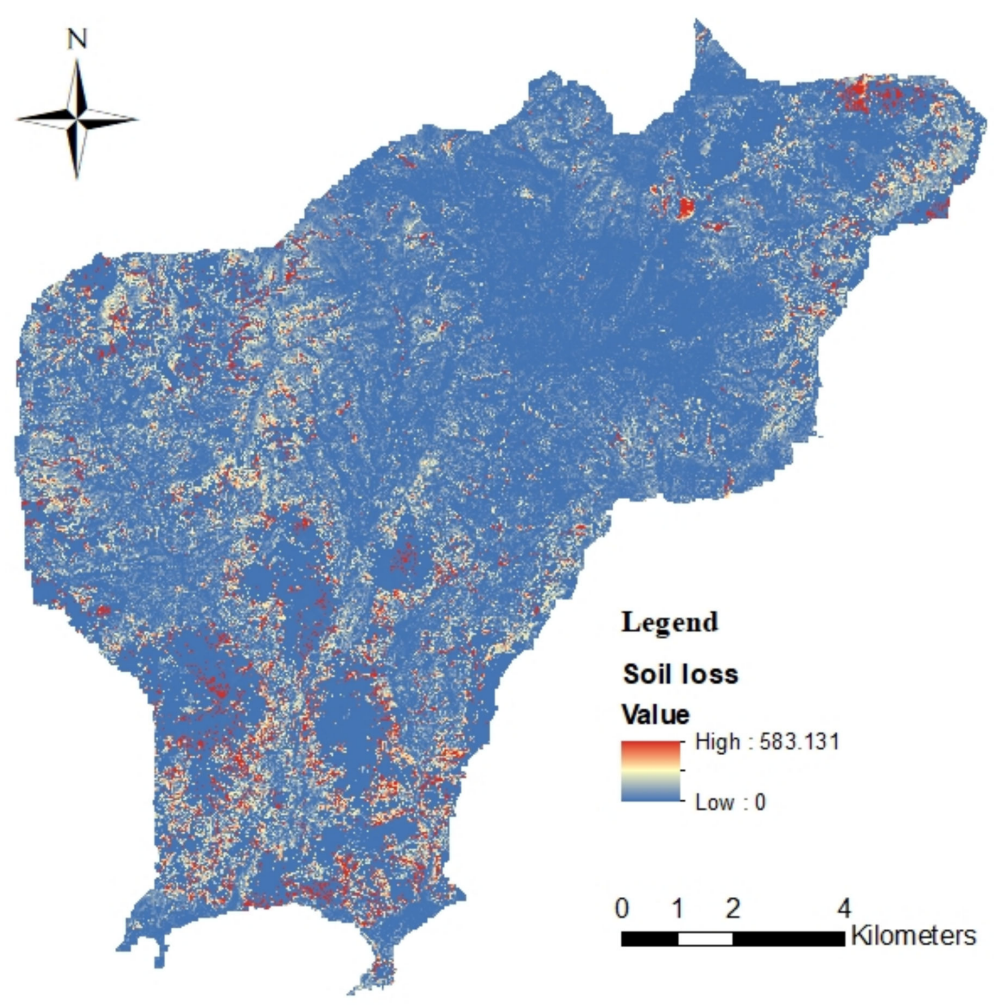

Figure 21. Soil loss map with R-factor values derived from in situ data and C-factor values derived NDVI(vk) data.

According to scenario 5, the estimated soil loss ranged from 0 to $279 \mathrm{t} \mathrm{ha}^{-1}$ year $^{-1}$, with a mean value of $1.95 \mathrm{t} \mathrm{ha}^{-1}$ year $^{-1}$.

According to scenario 6 , the estimated soil loss ranged from 0 to $583 \mathrm{t} \mathrm{ha}^{-1} \mathrm{year}^{-1}$, with a mean value of $3.24 \mathrm{t} \mathrm{ha}^{-1}$ year $^{-1}$.

Table 10 lists the values for the mean annual soil loss with R-factor values derived from GPM data and rain gauge data and C-factor values derived from literature and NDVI data, respectively.

Table 10. Mean annual soil loss rates for scenarios 1, 2, 5, and 6.

\begin{tabular}{ccccc}
\hline & Scenario 1 & Scenario 2 & Scenario 5 & Scenario 6 \\
\cline { 2 - 5 } & \multicolumn{2}{c}{ R-Factor Derived from GPM Data } & R-Factor Derived from Rain Gauge Data \\
\cline { 2 - 5 } & $\begin{array}{c}\text { C-Factor Derived } \\
\text { from Literature }\end{array}$ & $\begin{array}{c}\text { C-Factor Derived } \\
\text { from NDVI (vk) }\end{array}$ & $\begin{array}{c}\text { C-Factor Derived } \\
\text { from Literature }\end{array}$ & $\begin{array}{c}\text { C-Factor Derived } \\
\text { from NDVI (vk) }\end{array}$ \\
\hline $\begin{array}{c}\text { Mean annual } \\
\text { soil erosion } \\
\left(\mathrm{t} \mathrm{ha}^{-1} \text { year }^{-1}\right)\end{array}$ & 2.59 & 4.63 & 1.95 & 3.24 \\
\hline
\end{tabular}

The annual soil erosion rates obtained using $\mathrm{R}$-factor values derived from rain gauge data were slightly underestimated in comparison with those obtained using R-factor values derived from GPM data. This underestimation was due to the differences in the data used to derive R-factor values (satellite-based data vs. ground-based data).

\subsection{Landscape Metrics Analysis}

Land-cover maps for 2010 and 2020 were derived using the random forest classifier (using 20 trees). Corine Land Cover level 3 classes were aggregated to the following 6 classes (urban, cropland, grassland, woodland and forest, heathland and shrub, sparsely vegetated areas) to simplify the analysis of change. 
The classification results were subsequently validated using Google earth imagery, with accuracies exceeding 75\% for the two dates with Kappa statistics of $68 \%$ and $64 \%$ for 2010 and 2020, respectively. After classification, change-detection analysis was carried out.

The classified images are shown in Figure 22. The selected metrics were calculated at the class level using an $8 \times 8 \mathrm{~m}$ cell neighborhood rule in FRAGSTAT. Table 11 illustrates the values for the calculated landscape metrics.
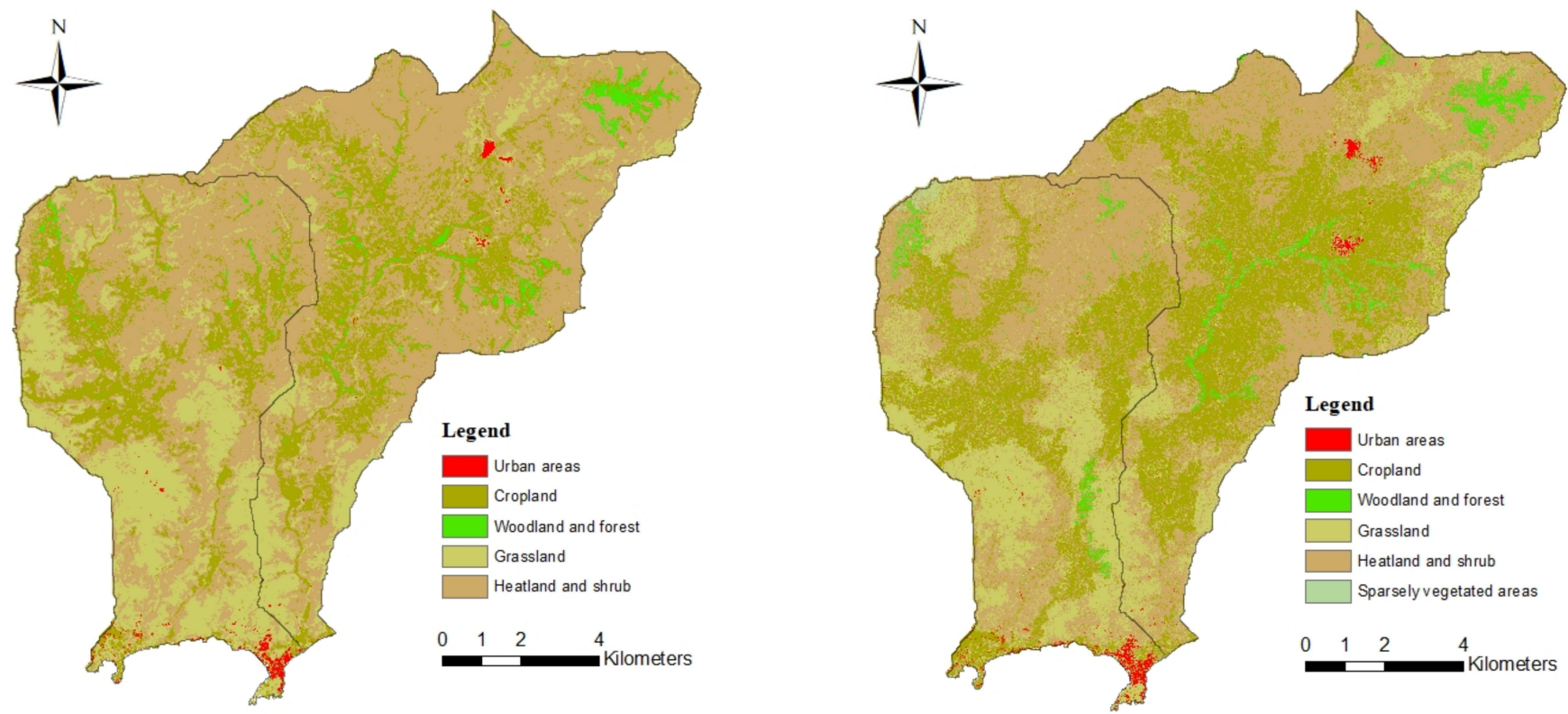

Figure 22. Classified LULC maps of Paleochora for 2010 (left) and 2020 (right).

Table 11. Results for the landscape metrics.

\begin{tabular}{|c|c|c|c|c|c|c|c|c|c|}
\hline & \multirow{2}{*}{ Land Cover Classes } & \multicolumn{2}{|c|}{ Total Area } & \multicolumn{2}{|c|}{$N P$} & \multicolumn{2}{|c|}{$P D$} & \multicolumn{2}{|c|}{$E D$} \\
\hline & & \multirow{2}{*}{\begin{tabular}{|c|}
2010 \\
71.28
\end{tabular}} & \multirow{2}{*}{$\begin{array}{c}\mathbf{2 0 2 0} \\
97.74\end{array}$} & \multirow{2}{*}{$\begin{array}{c}2010 \\
140\end{array}$} & \multirow{2}{*}{\begin{tabular}{|c|}
2020 \\
243
\end{tabular}} & \multirow{2}{*}{$\begin{array}{c}2010 \\
0.93\end{array}$} & \multirow{2}{*}{$\begin{array}{c}2020 \\
1.61\end{array}$} & \multirow{2}{*}{$\begin{array}{c}2010 \\
2.79\end{array}$} & \multirow{2}{*}{$\begin{array}{c}2020 \\
4.56\end{array}$} \\
\hline 1 & Urban & & & & & & & & \\
\hline 2 & Cropland & 3218.58 & 4673.43 & 2259 & 3887 & 15.04 & 25.89 & 100.45 & 157.88 \\
\hline 3 & Woodland and forest & 247.41 & 377.37 & 480 & 837 & 3.19 & 5.57 & 10.23 & 20.18 \\
\hline 4 & Grassland & 2947.68 & 2768.31 & 1458 & 3336 & 9.71 & 22.22 & 61.47 & 95.58 \\
\hline 5 & Heathland and shrub & 8527.05 & 7077.69 & 1253 & 3977 & 8.34 & 26.49 & 142.23 & 202.5 \\
\hline 6 & Sparsely vegetated areas & & 18.72 & & 46 & & 0.3 & & 1.12 \\
\hline \multirow{2}{*}{\multicolumn{2}{|c|}{ Land Cover Classes }} & \multicolumn{2}{|c|}{$L P I$} & \multicolumn{2}{|c|}{ ENN_AM } & \multicolumn{2}{|c|}{ PLAND } & \multicolumn{2}{|c|}{ SPLIT } \\
\hline & & 2010 & 2020 & 2010 & 2020 & 2010 & 2020 & 2010 & 2020 \\
\hline 1 & Urban & 0.15 & 0.14 & 140 & 243 & 0.47 & 0.65 & 337133.02 & 231397.27 \\
\hline 2 & Cropland & 8.21 & 18.56 & 2259 & 3887 & 21.44 & 31.12 & 110.97 & 26.40 \\
\hline 3 & Woodland and forest & 0.12 & 0.43 & 480 & 837 & 1.64 & 2.51 & 51675.1 & 41194.35 \\
\hline 4 & Grassland & 4.1 & 2.81 & 1458 & 3336 & 19.63 & 18.43 & 312.88 & 444.27 \\
\hline 5 & Heathland and shrub & 49.18 & 20.64 & 1253 & 3977 & 56.8 & 47.14 & 4.12 & 20.22 \\
\hline 6 & Sparsely vegetated areas & & 0.039 & & 46 & & 0.12 & & 4719625.27 \\
\hline
\end{tabular}

NP: Number of Patches; PD: Patch Density; ED: Edge Density; LPI: Largest Patch Index; ENN_AM: Euclidean Nearest Neighbor Distance Area-Weighted Mean; PLAND: Percentage of Landscape; SPLIT: Split index. 
Land cover classes across the two dates (2010 and 2020) showed that heathland and shrub (5) was the dominant class in the study area according to PLAND metric values. For 2010, although the NP value for the heathland and shrub class (5) was lower than the NP values for the cropland (2) and grassland (4) classes, the LPI, ED, and TA values were higher than for the other classes. These values showed that compact and related patches were concentrated in this class; however, the values for the area-edge metrics decreased from 2010 to 2020.

Urban areas (1) were independently identified as the most passive class in terms of $P D$, $N P$, and PLAND values for the two dates, as their patches were too small and dispersed. In fact, the ENN_AM, which is weighted with respect to the patch size, determines the neighborhood relations of the patches in terms of proximity. According to this metric, patches belonging to urban areas (1) were too far from each other (showing the highest ENN_AM values); however, there was a slight expansion in urban areas between 2010 and 2020.

Both cropland (2) and grassland (4) classes showed quite high values for NP and $P D$. When considered along with the low values for $L P I$, these results suggest that these classes are undergoing fragmentation over time. Additionally, cropland (2) and grassland (4) classes, which had the highest LSI values, have complex structures; however, in terms of their ED values, they were lower than the heathland and shrub class (5). This showed that patches from the cropland (2) and grassland (4) classes had started to lose their core properties and their edge relations had been weakened.

The woodland and forest class (3) was identified as the class with the highest class fragmentation. Even though the NP values were much higher compared to the urban areas class (1), which covered the smallest surface area in the study area, the woodland and forest class (3) had lower LPI values (0.12 and 0.43 for 2010 and 2020, respectively). These values showed that the patches in the woodland and forest class (3) are small, underdeveloped, and according to the SPLIT and ENN_AM values, they are scattered and not connected.

The sparsely vegetated areas class (6) was only identified in 2020. It had the lowest PLAND and LPI metric values. It was the smallest class in terms of area, patch density, and patch number.

The overall assessment of the metrics showed that the heathland and shrub class (5) dominated the landscape - its patches are both large and dense. Both cropland (2) and grassland (4) classes were scattered in the region as unconnected small units. Woodland and forest (3) classes were scattered and disjointed. The urban areas class (1) had the lowest values in terms of area, patch density, and patch number. The sparsely vegetated areas class (6) was only mapped in 2020. The invaded grassland (4) and heathland and shrub (5) classes decreased from 2010 to 2020 , giving way to the invasion of the sparsely vegetated areas class (6).

Multiple linear regression (MLR) methodology was applied in order to both spatially and quantitively correlate (Table 12) the soil erosion rate (dependent variable) with landscape metrics (independent variables).

Table 12. Landscape metrics and mean soil erosion rate for 2020 for each land cover class.

\begin{tabular}{ccccccccccc}
\hline & \multicolumn{3}{c}{$\begin{array}{c}\text { Mean Soil Erosion Rate } \\
\text { Scenario No. }\end{array}$} & \multicolumn{5}{c}{ Landscape Metrics (2020) } \\
\cline { 2 - 12 } Land Cover Classes & $\mathbf{1}$ & $\mathbf{2}$ & $\mathbf{5}$ & $\mathbf{6}$ & $\mathbf{P D}$ & $\mathbf{E D}$ & $\mathbf{L P I}$ & ENN_AM & PLAND & SPLIT \\
\hline Cropland & 6 & 4.73 & 4.34 & 4.014 & 25.9 & 157.9 & 18.6 & 61.64 & 31.12 & 26.4 \\
\hline Woodland and forest & 0.67 & 2.06 & 0.61 & 2.6 & 5.57 & 20.18 & 0.43 & 81.42 & 2.51 & 41194.35 \\
\hline Grassland & 3.06 & 5.24 & 1.16 & 2.89 & 22.2 & 95.58 & 2.81 & 63.47 & 18.43 & 444.27 \\
\hline Heathland and shrub & 0.1 & 6.62 & 0.06 & 4.33 & 26.5 & 202.5 & 20.6 & 60.44 & 47.14 & 20.22 \\
\hline
\end{tabular}


The following table (Table 13) summarizes the results from the MLR modeling, which were obtained on the basis of the data set and the MLR modeling approach that was applied to determine the relationships between landscape metrics and the mean soil erosion rate per land cover class.

Table 13. Correlation between landscape metrics values and mean soil erosion.

\begin{tabular}{|c|c|c|c|c|c|c|c|c|}
\hline & \multirow{2}{*}{ MLR } & \multicolumn{6}{|c|}{ Landscape Metrics } & \multirow{2}{*}{ Correlation } \\
\hline & & $P D$ & $E D$ & $L P I$ & ENN_AM & PLAND & SPLIT & \\
\hline \multirow{2}{*}{ Scenario 1} & $\mathrm{R}^{2}$ & 0.45 & 0.34 & 0.18 & 0.92 & 0.3 & 0.97 & \multirow{2}{*}{$\begin{array}{l}\text { ENN_AM } \\
\text { SPLIT }\end{array}$} \\
\hline & $p$ value & 0.2 & 0.3 & 0.47 & 0.009 & 0.33 & 0.001 & \\
\hline \multirow{2}{*}{ Scenario 2} & $\mathrm{R}^{2}$ & 0.4 & 0.5 & 0.38 & 0.028 & 0.56 & 0 & \multirow{2}{*}{ No correlation } \\
\hline & $p$ value & 0.24 & 0.17 & 0.26 & 0.78 & 0.14 & 0.99 & \\
\hline \multirow{2}{*}{ Scenario 5} & $\mathrm{R}^{2}$ & 0.42 & 0.31 & 0.15 & 0.9 & 0.28 & 0.95 & \multirow{2}{*}{$\begin{array}{c}\text { ENN_AM } \\
\text { SPLIT }\end{array}$} \\
\hline & $p$ value & 0.23 & 0.32 & 0.51 & 0.014 & 0.35 & 0.004 & \\
\hline \multirow{2}{*}{ Scenario 6} & $\mathrm{R}^{2}$ & 0.8 & 0.95 & 0.93 & 0.5 & 0.93 & 0.43 & \multirow{2}{*}{$\begin{array}{c}P D, E D, L P I, \\
P L A N D\end{array}$} \\
\hline & $p$ value & 0.039 & 0.004 & 0.006 & 0.14 & 0.008 & 0.22 & \\
\hline
\end{tabular}

NP: Number of Patches; PD: Patch Density; ED: Edge Density; LPI: Largest Patch Index; ENN_AM: Euclidean Nearest Neighbor Distance Area-Weighted Mean; PLAND: Percentage of Landscape; SPLIT: Split index; Values in bold are significant at $p<0.05$.

The mean soil erosion rate per land cover class for the RUSLE model implemented with R-factor values derived from in situ data and C-factor values derived from NDVI data (Scenario 6) with the landscape metrics analysis for the year 2020 exhibited highly positive correlations with most of the landscape metrics; thus, higher PD intensifies soil erosion and lower PD causes more erosion. In fact, for cropland (2) and woodland and forest (3) classes, the PD increased between 2010 and 2020 by almost $50 \%$. Although these classes were undergoing expansion, they were highly fragmented and their patches were scattered and disconnected. This finding was confirmed by the results of the study by Huang et al. [52]. Their results showed that the overall level of soil erosion declined between 2010 and 2020, while the estimated PD metric values for the same period decreased by almost $50 \%$.

Over one decade, between 2010 and 2020, the PD values of grassland (4) and heathland and shrub (5) classes increased, indicating that PN increased and LPI decreased. Ouyang et al. [53] explained that grassland patches mitigate soil erosion mainly at the edge of the patch, not across the whole patch area.

Consequently, it seems that the landscape pattern influences soil erosion. In fact, higher interspersion (SPLIT metric) and patch numbers (NP metric) for land cover classes proved to significantly accelerate soil erosion.

\subsection{Morphometric Parameters Analysis}

Watersheds and sub-watersheds can be prioritized on the basis of morphometric parameters. For prioritization of sub-watersheds in water resources management, the morphometric analysis uses certain very crucial linear and shape morphometric parameters. Linear parameters such as the drainage density, stream frequency, bifurcation ratio, and texture ratio have direct relationships with erodibility, whereas shape parameters such as the elongation ratio, circulatory ratio, form factor, and compactness ratio have inverse relationships with erodibility $[54,55]$.

Greater values for linear parameters enhance the runoff potential and the erodibility; hence, each sub-watershed was ranked depending on the values of different geomorphological parameters. The highest value for the linear parameters was given a rating of 1 , the next highest value was given a rating of 2 , and so on, as these geomorphological parameters generally show positive correlations with soil erosion. The lowest value was rated last in the series of numbers. 
In contrast, for shape parameters, the lowest value was given a rating of 1 , the next lowest value was given a rating of 2, and so on, as these parameters show negative correlations with soil erosion.

The prioritization of both the catchments was carried out by calculating the compound factor values. The compound factor ( $\mathrm{Cf}$ ) was calculated by adding up all ranks of linear and shape parameters and then dividing this number by the number of all parameters (which here was 10) (Table 14). The highest prioritized rank was assigned to the catchment with the lowest compound factor, and vice versa.

Table 14. Prioritization of catchments based on morphometric parameters.

\begin{tabular}{|c|c|c|c|c|c|c|c|c|c|c|c|c|}
\hline & \multicolumn{5}{|c|}{ Linear Parameters } & \multicolumn{5}{|c|}{ Shape Parameters } & \multirow{2}{*}{ Compound Factor } & \multirow{2}{*}{ Priority } \\
\hline & $\mathbf{R b}$ & Dd & $\mathbf{F u}$ & $\mathbf{T}$ & Lo & Rf & Bs & $\operatorname{Re}$ & $\mathrm{Cc}$ & Rc & & \\
\hline Kakodikianos & 2 & 2 & 2 & 2 & 1 & 1 & 2 & 1 & 2 & 1 & 1.6 & 2 \\
\hline Pelekaniotis & 1 & 1 & 1 & 1 & 2 & 2 & 1 & 2 & 1 & 2 & 1.4 & 1 \\
\hline
\end{tabular}

According to the ranking, the Pelekaniotis catchment seemed to be more prone to soil erosion than the Kakodikianos catchment. Table 15 summarizes the mean soil erosion rates for each catchment under the different RUSLE scenarios.

Table 15. Mean soil erosion rates for each catchment.

\begin{tabular}{lccc}
\hline & & \multicolumn{2}{c}{ Mean Soil Erosion Rate (2020) } \\
\cline { 3 - 4 } & & Kakodikianos & Pelekaniotis \\
\hline Scenario 1 & R-GPM, C-lit & 2.92 & 2.19 \\
Scenario 2 & R-GPM, C-ndvi & 4.72 & 4.52 \\
Scenario 5 & R-in situ, C-lit & 1.8 & 2.14 \\
Scenario 6 & R-in situ, C-ndvi & 2.54 & 4.06 \\
\hline
\end{tabular}

The prioritization ranking based on morphometric parameters was positively correlated with both scenarios 5 and 6; however, for scenarios 1 and 2, it was negatively correlated (Tables 15 and 16).

Table 16. Priority based on soil loss estimation and morphometric parameter analysis.

\begin{tabular}{cccccc}
\hline & \multicolumn{5}{c}{ Priority Based On } \\
\cline { 2 - 5 } Catchment & \multicolumn{4}{c}{ Soil Loss Estimation } \\
\cline { 2 - 5 } & Scenario 1 & Scenario 2 & Scenario 5 & Scenario 6 & 2 \\
\hline Kakodikianos & 1 & 1 & 2 & 2 & 1 \\
Pelekaniotis & 2 & 2 & 1 & 1 & 2 \\
\hline
\end{tabular}

The same prioritization procedure was likewise conducted at the sub-catchment scale to detect the areas that were highly vulnerable to soil erosion according to the morphometric parameters. Kakodikianos catchment was divided into 52 sub-catchments, while Pelekaniotis catchment was split into 73 sub-catchments. All sub-catchments were clustered into following three priority classes based on the range of compound factor $\left(\mathrm{C}_{\mathrm{f}}\right)$ values and according to the natural breaks method (Figure 23): high priority (31.78-52.77), moderate priority (52.78-71.55), and low priority (71.56-95.55).

According to the above-mentioned classification based on morphometric parameters, $36 \%$ of the sub-catchments were classified as high priority, $26.4 \%$ of the sub-catchments were classified as moderate priority, and $37.6 \%$ of the sub-catchments were classified as low priority. 


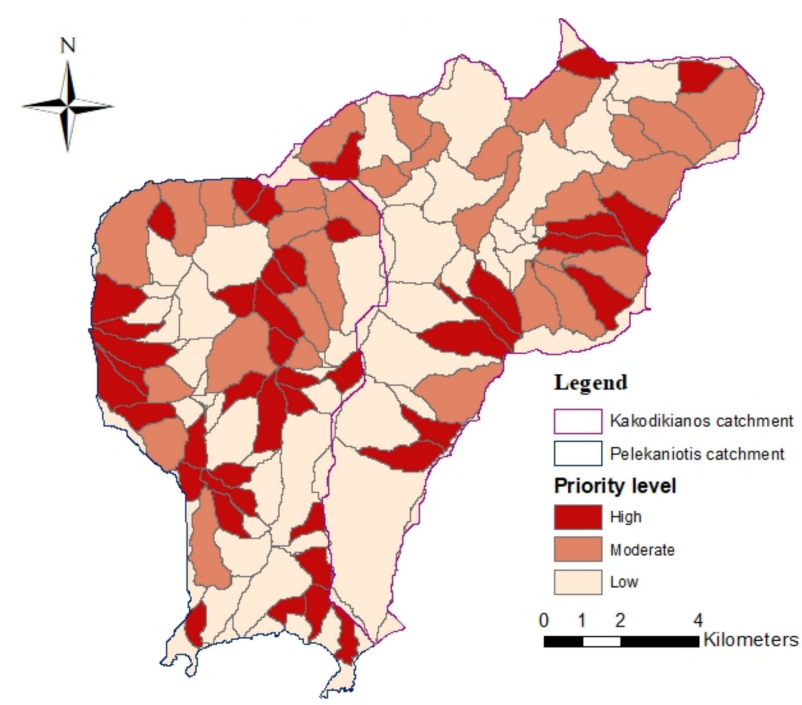

Figure 23. Priority levels of the sub-catchments based on morphometric parameters.

On the other hand, the priority levels of the sub-catchments based on mean soil erosion rates are illustrated in the following figure (Figure 24). Three soil erosion classes, namely low, medium, and high, were categorized based on the natural breaks method. The highest priority indicates the greatest degree of erosion in a particular sub-catchment, meaning it requires soil conservation practices.

The integration of the results from the morphometric analysis method and the RUSLE was achieved by overlaying the produced maps in order to identify the common subcatchments falling under each priority category (Table 17).

Table 17. Percentage of common sub-catchments falling under each priority category.

\begin{tabular}{cccccc}
\hline & & Scenario 1 & Scenario 2 & Scenario 5 & Scenario 6 \\
\hline \multirow{3}{*}{ Priority (\%) } & High & 4.8 & 6.4 & 0.8 & 6.4 \\
\cline { 2 - 6 } & Moderate & 8.8 & 11.2 & 7.2 & 26 \\
\cline { 2 - 6 } & Low & 16.8 & 29.6 & 21.6 & 19 \\
\hline \multicolumn{2}{c}{ Total (\%) } & 30.4 & 47.2 & 29.6 & 51 \\
\hline
\end{tabular}

Based on the linear and shape morphometric parameter analysis, the prioritization results at the catchment scale showed that Pelekaniotis catchment was more prone to soil erosion than Kakodikianos catchment. This finding seemed to be consistent with the result from the RUSLE model implemented with R-factor values derived from in situ data and C-factor values derived from literature and NDVI data, respectively (scenarios 2 and 6).

At the sub-catchment scale, the morphometric parameters analysis demonstrated that $36 \%$ of the sub-catchments were ranked as high priority, meaning high erosion risk. Through integration of the results of the morphometric analysis and RUSLE implemented with C-factor values derived from NDVI and R-factor values derived from GPM and in situ data, respectively, $6 \%$ of the sub-catchments were classified as high priority. These sub-catchments were located in relatively steep slope areas (averaging around $41 \%$ ). The evaluation of the morphometric parameters at the sub-catchment scale is more advantageous, since this detects the most soil erosion-prone areas that require the implementation of soil and water conservation practices. 


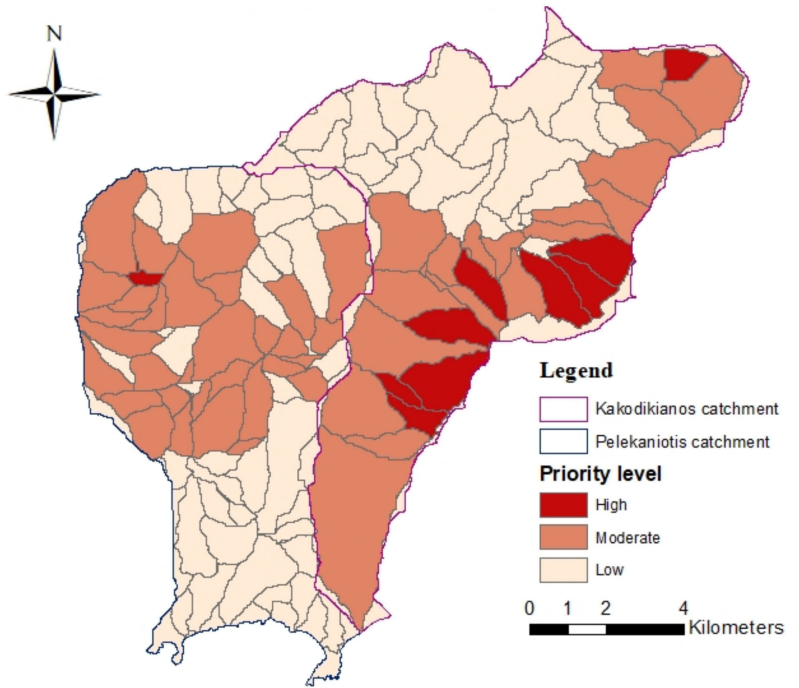

(a)

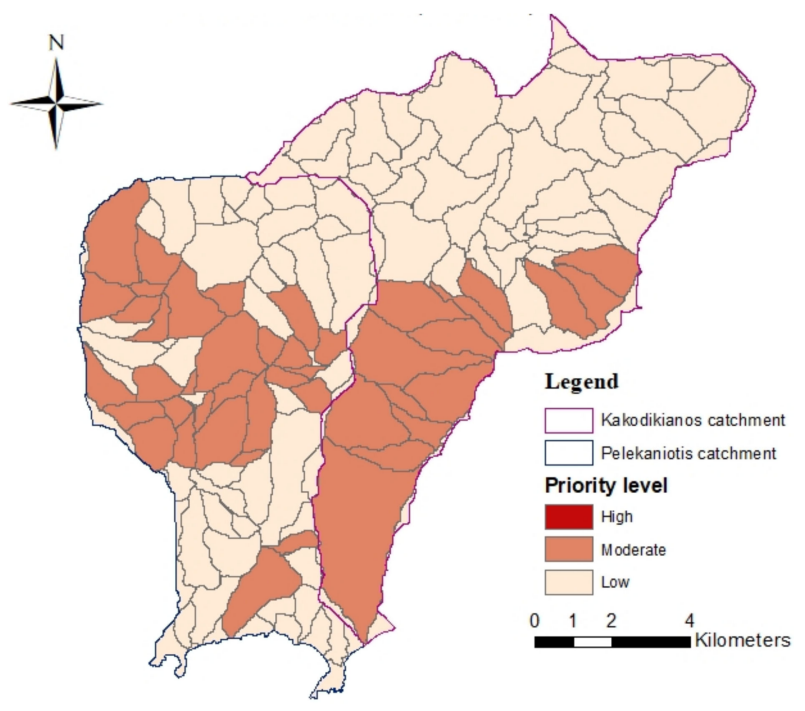

(c)

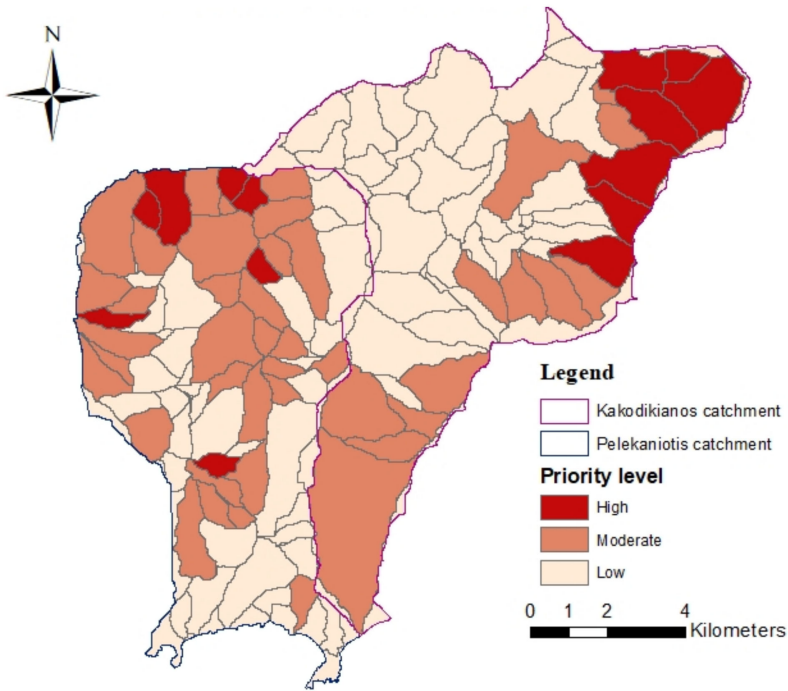

(b)

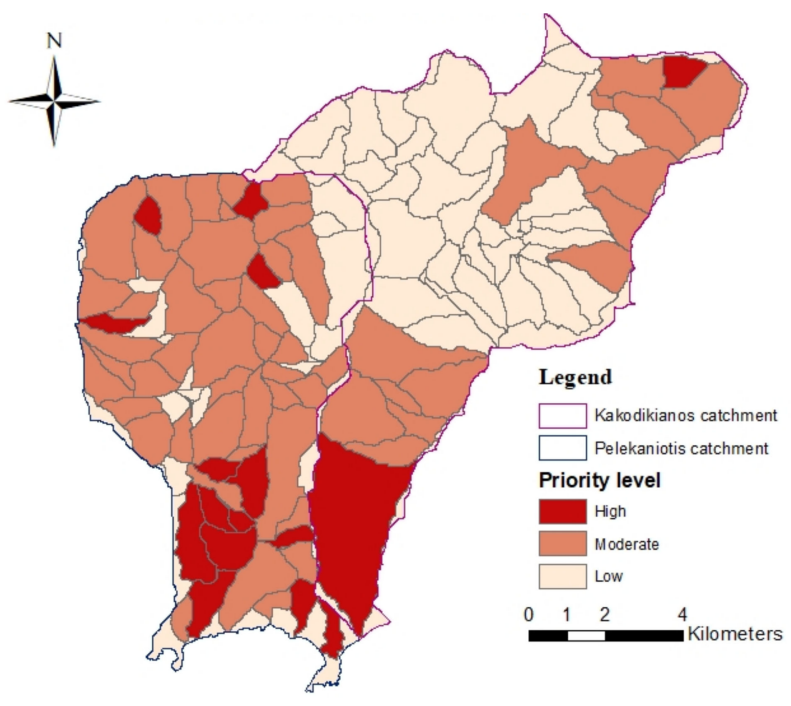

(d)

Figure 24. Priority levels of the sub-catchments based on mean soil erosion: (a) scenario 1; (b) scenario 2; (c) scenario 5; (d) scenario 6 .

\section{Conclusions}

Soil erosion is a universal concern that mainly impacts the environment and different habitats. It is crucial to assess soil erosion rates and map the spatial distribution of soil erosion in order to plan conservation and management practices.

The current study proved that the RUSLE model can be efficiently applied at the catchment scale to estimate soil erosion rates through the integration of GIS and remote sensing techniques. The highest soil loss rates were found in sparsely vegetated areas. The high erosion values depicted for natural grassland and pasture areas can be attributed to the increasing levels of livestock and inappropriate grazing practices, which further intensify the soil degradation.

The RUSLE can, therefore, be replicated in other catchments in Chania in particular and in Crete island in general for the estimation and delimitation of erosion-prone areas.

Although relatively modest data are required for the RUSLE, the soil erosion rates are often overestimated for low rainfall events, while they are underestimated for high rainfall events [56]. This variation can be explained by the fact that runoff is incorporated within 
the R-factor. Additionally, the RUSLE assesses soil loss only for sheet and rill erosion, but it does not account other types of erosion (gully erosion, channel erosion, bank erosion, or extreme events such as landslides) [25,57].

The landscape metric analysis showed that most of the estimated landscape metrics had a significant correlation with the soil erosion rate, which was assessed using the RUSLE, with R-factor values derived from in situ data and C-factor values derived from NDVI data. It can be concluded that the landscape pattern has a positive impact on soil erosion.

Regarding the morphometric parameter analysis, the prioritization results at the catchment scale seemed to be consistent with the result for the RUSLE implemented with $\mathrm{R}$-factor values derived from in situ data and $\mathrm{C}$-factor values derived from literature and NDVI data, respectively. At the sub-catchment scale, the morphometric parameter analysis seemed to be consistent with the results for the RUSLE implemented using C-factor values derived from NDVI data and R-factor values derived from GPM and in situ data, respectively.

The overall evaluation of the three approaches (RUSLE model, landscape metrics, and morphometric parameters) showed that the RUSLE model implemented with R-factor values derived from in situ data and C-factor values derived from NDVI data, was the most relevant scenario, which was correlated with both the landscape metric and morphometric parameter analyses. In this scenario, the mean soil erosion rate in the study area was about $3.24 \mathrm{t} \mathrm{ha}^{-1}$ year $^{-1}$.

The current study revealed the fact that the integrated three-fold approach of soil erosion modeling, landscape fragmentation study, and estimation of morphometric parameters can complement each other in the efficient monitoring of soil loss at the catchment scale. In most of the relevant studies, the researchers implemented the specific approaches separately. In our study, we highlighted the fact that the simultaneous application of these different approaches in the GIS environment can offer a new option for soil erosion modelers, who usually focus only on applying empirical models and not on investigating the land use and morphological regimes within the study areas. In addition, this approach is considered to be extremely useful in cases where in situ soil loss data are not available, because landscape and morphometric approaches can effectively support the final results, as estimated from models such as the RUSLE.

Author Contributions: Conceptualization, I.B., D.D.A., C.K.; methodology, I.B., D.D.A., C.K.; software, I.B.; validation, I.B., D.D.A., C.K.; formal analysis, I.B; investigation, I.B.; resources, D.D.A.; data curation, I.B.; writing —original draft preparation, I.B.; writing-review and editing, I.B., D.D.A., C.K.; visualization, I.B., D.D.A., C.K.; supervision, D.D.A., C.K. All authors have read and agreed to the published version of the manuscript.

Funding: This research received no external funding.

Acknowledgments: We acknowledge the National Observatory of Athens for providing the observational data used in the analysis.

Conflicts of Interest: The authors declare no conflict of interest.

\section{References}

1. Polykretis, C.; Alexakis, D.D.; Grillakis, M.G.; Manoudakis, S. Assessment of intra-annual and inter-annual variabilities of soil erosion in Crete Island (Greece) by incorporating the dynamic "nature" of R and C-factors in RUSLE modeling. Remote Sens. 2020, 12, 2439. [CrossRef]

2. Eisazadeh, L.; Sokouti, R.; Homaee, M.; Pazira, E. Comparison of empirical models to estimate soil erosion and sediment yield in micro catchments. Eurasian J. Soil Sci. 2012, 1, 28-33. [CrossRef]

3. Kouli, M.; Soupios, P.; Vallianatos, F. Soil erosion prediction using the Revised Universal Soil Loss Equation (RUSLE) in a GIS framework, Chania, Northwestern Crete, Greece. Environ. Geol. 2009, 57, 483-497. [CrossRef]

4. Karydas, C.G.; Sekuloska, T.; Silleos, G.N. Quantification and site-specification of the support practice factor when mapping soil erosion risk associated with olive plantations in the Mediterranean island of Crete. Environ. Monit. Assess. 2009, 149, 19-28. [CrossRef]

5. Koirala, P.; Thakuri, S.; Joshi, S.; Chauhan, R. Estimation of Soil Erosion in Nepal using a RUSLE modeling and geospatial tool. Geoscience 2019, 9, 147. [CrossRef] 
6. Phinzi, K.; Ngetar, N.S. The assessment of water-borne erosion at catchment level using GIS-based RUSLE and remote sensing: A review. Int. Soil Water Conserv. Res. 2019, 7, 27-46. [CrossRef]

7. Alexakis, D.D.; Hadjimitsis, D.G.; Agapiou, A. Integrated use of remote sensing, GIS and precipitation data for the assessment of soil erosion rate in the catchment area of "Yialias" in Cyprus. Atmos. Res. 2013, 131, 108-124. [CrossRef]

8. Kouli, M.; Kalisperi, D.; Soupios, P.; Vallianatos, F. Modeling soil erosion processes in watersheds and the relation between soil loss with geomorphic and chemical parameters. Watersheds Manag. Restor. Environ. Impact 2010, 65-114.

9. Shi, Z.H.; Ai, L.; Li, X.; Huang, X.D.; Wu, G.L.; Liao, W. Partial least-squares regression for linking land-cover patterns to soil erosion and sediment yield in watersheds. J. Hydrol. 2013, 498, 165-176. [CrossRef]

10. Kumar Pradhan, R.; Srivastava, P.K.; Maurya, S.; Kumar Singh, S.; Patel, D.P. Integrated framework for soil and water conservation in Kosi River Basin. Geocarto Int. 2020, 35, 391-410. [CrossRef]

11. Cham, D.D.; Son, N.T.; Minh, N.Q.; Thanh, N.T.; Dung, T.T. An analysis of shoreline changes using combined multitemporal remote sensing and digital evaluation model. Civ. Eng. J. 2020, 6, 1-10. [CrossRef]

12. Panagos, P.; Christos, K.; Cristiano, B.; Ioannis, G. Seasonal monitoring of soil erosion at regional scale: An application of the G2 model in crete focusing on agricultural land uses. Int. J. Appl. Earth Obs. Geoinf. 2014, 27, 147-155. [CrossRef]

13. Polykretis, C.; Grillakis, M.G.; Alexakis, D.D. Exploring the impact of various spectral indices on land cover change detection using change vector analysis: A case study of Crete Island, Greece. Remote Sens. 2020, 12, 319. [CrossRef]

14. Retalis, A.; Katsanos, D.; Tymvios, F.; Michaelides, S. Comparison of GPM imerg and TRMM 3B43 products over Cyprus. Remote Sens. 2020, 12, 3212. [CrossRef]

15. Panagos, P.; Meusburger, K.; Ballabio, C.; Borrelli, P.; Alewell, C. Soil erodibility in Europe: A high-resolution dataset based on LUCAS. Sci. Total Environ. 2014, 479-480, 189-200. [CrossRef]

16. Niipele, J.N.; Chen, J. The usefulness of alos-palsar dem data for drainage extraction in semi-arid environments in The lishana sub-basin. J. Hydrol. Reg. Stud. 2019, 21, 57-67. [CrossRef]

17. Shawky, M.; Moussa, A.; Hassan, Q.K.; El-Sheimy, N. Pixel-based geometric assessment of channel networks/orders derived from global spaceborne digital elevation models. Remote Sens. 2019, 11, 235. [CrossRef]

18. SUHET. Sentinel-2 User Handbook; European Comission: Brussels, Belgium, 2015.

19. Panagos, P.; Borrelli, P.; Meusburger, K.; van der Zanden, E.H.; Poesen, J.; Alewell, C. Modelling the effect of support practices (P-factor) on the reduction of soil erosion by water at European scale. Environ. Sci. Policy 2015, 51, 23-34. [CrossRef]

20. Panagos, P.; Meusburger, K.; Alewell, C.; Montanarella, L. Soil erodibility estimation using LUCAS point survey data of Europe. Environ. Model. Softw. 2012, 30, 143-145. [CrossRef]

21. Oliveira, J.A.; Dominguez, J.M.L.; Nearing, M.A.; Oliveira, P.T.S. A GIS-Based procedure for automatically calculating soil loss from the universal soil loss Equation: GISus-M. Appl. Eng. Agric. 2015, 31, 907-917. [CrossRef]

22. Panagos, P.; Borrelli, P.; Meusburger, K.; Alewell, C.; Lugato, E.; Montanarella, L. Estimating the soil erosion cover-management factor at the European scale. Land Use Policy 2015, 48, 38-50. [CrossRef]

23. Alkharabsheh, M.M.; Alexandridis, T.K.; Bilas, G.; Misopolinos, N.; Silleos, N. Impact of Land Cover Change on Soil Erosion Hazard in Northern Jordan Using Remote Sensing and GIS. Procedia Environ. Sci. 2013, 19, 912-921. [CrossRef]

24. Wischmeier, W.H.; Smith, D.D. Predicting Rainfall Erosion Losses; Department of Agriculture, Science and Education Administration: Corvallis, OR, USA, 1978.

25. Rubianca, B.; Bethanna, J.; Deborah, M.; Kevin, N. A review of the Revised Universal Soil Loss Equation RUSLE With a view to increasing its global applicability and improving soil loss estimates. Hydrol. Earth Syst. Sci. 2018, 22, 6059-6086.

26. Renard, K.G.; Freimund, J.R. Using monthly precipitation data to estimate the R-factor in the revised USLE. J. Hydrol. 1994, 157, 287-306. [CrossRef]

27. De Santos Loureiro, N.; de Azevedo Coutinho, M. A new procedure to estimate the RUSLE EI30 index, based on monthly rainfall data and applied to the Algarve region, Portugal. J. Hydrol. 2001, 250, 12-18. [CrossRef]

28. Grillakis, M.G.; Polykretis, C.; Alexakis, D.D. Past and projected climate change impacts on rainfall erosivity: Advancing our knowledge for the eastern Mediterranean island of Crete. Catena 2020, 193, 104625. [CrossRef]

29. Alexakis, D.D.; Tsanis, I.K. Comparison of multiple linear regression and artificial neural network models for downscaling TRMM precipitation products using MODIS data. Environ. Earth Sci. 2016, 75. [CrossRef]

30. Zhan, C.; Han, J.; Hu, S.; Liu, L.; Dong, Y. Spatial Downscaling of GPM Annual and Monthly Precipitation Using Regression-Based Algorithms in a Mountainous Area. Adv. Meteorol. 2018, 2018. [CrossRef]

31. Kruk, E.; Klapa, P.; Ryczek, M.; Ostrowski, K. Influence of dem elaboration methods on the usle model topographical factor parameter on steep slopes. Remote Sens. 2020, 12, 3540. [CrossRef]

32. Desmet, P.J.J.; Govers, G. A GIS procedure for automatically calculating the USLE LS factor on topographically complex landscape units. J. Soil Water Conserv. 1996, 51, 427-433.

33. McCool, D.K.; Foster, G.R.; Mutchler, C.K.; Meyer, L.D. Revised slope length factor for the universal soil loss equation. Trans. Am. Soc. Agric. Eng. 1989, 32, 1571-1576. [CrossRef]

34. Ozsahin, E.; Duru, U.; Eroglu, I. Land use and land cover changes (LULCC), a key to understand soil erosion intensities in the Maritsa Basin. Water 2018, 10, 335. [CrossRef]

35. Mondal, P.; Liu, X.; Fatoyinbo, T.E.; Lagomasino, D. Evaluating combinations of sentinel-2 data and machine-learning algorithms for mangrove mapping in West Africa. Remote Sens. 2019, 11, 2928. [CrossRef] 
36. Van der Knijff, J.M.; Jones, R.J.A.; Montanarella, L. Soil Erosion Risk Assessment in Europe; Technical Report; Joint Research Centre European Soil Bureau: Brussels, Belgium, 2000; p. 32.

37. Durigon, V.L.; Carvalho, D.F.; Antunes, M.A.H.; Oliveira, P.T.S.; Fernandes, M.M. NDVI time series for monitoring RUSLE cover management factor in a tropical watershed. Int. J. Remote Sens. 2014, 35, 441-453. [CrossRef]

38. Karydas, C.G.; Gitas, I.Z.; Parcharidis, I.A.; Adediran, A.O. Creation of a land cover map of Crete, using SPOT satellite data. Geography 2002, 2, 167-171.

39. Alexakis, D.D.; Agapiou, A.; Hadjimitsis, D.G.; Retalis, A. Optimizing statistical classification accuracy of satellite remotely sensed imagery for supporting fast flood hydrological analysis. Acta Geophys. 2012, 60, 959-984. [CrossRef]

40. Almagro, A.; Thomé, T.C.; Colman, C.B.; Pereira, R.B.; Marcato Junior, J.; Rodrigues, D.B.B.; Oliveira, P.T.S. Improving cover and management factor (C-factor) estimation using remote sensing approaches for tropical regions. Int. Soil Water Conserv. Res. 2019, 7, 325-334. [CrossRef]

41. Zhang, X.; Liao, C.; Li, J.; Sun, Q. Fractional vegetation cover estimation in arid and semi-arid environments using: HJ-1 satellite hyperspectral data. Int. J. Appl. Earth Obs. Geoinf. 2012, 21, 506-512. [CrossRef]

42. Jing, X.; Yao, W.Q.; Wang, J.H.; Song, X.Y. A study on the relationship between dynamic change of vegetation coverage and precipitation in Beijing's mountainous areas during the last 20 years. Math. Comput. Model. 2011, 54, 1079-1085. [CrossRef]

43. Li, L.; Wang, Y.; Liu, C. Effects of land use changes on soil erosion in a fast developing area. Int. J. Environ. Sci. Technol. 2014, 11, 1549-1562. [CrossRef]

44. Alexakis, D.D.; Hadjimitsis, D.G.; Agapiou, A.; Themistocleous, K.; Retalis, A. Monitoring urban land cover using satellite remote sensing techniques and field spectroradiometric measurements: Case study of "Yialias" catchment area in Cyprus. J. Appl. Remote Sens. 2012, 6, 063603. [CrossRef]

45. Kumar, M.; Denis, D.M.; Singh, S.K.; Szabó, S.; Suryavanshi, S. Landscape Metrics for Assessment of Land Cover Change and Fragmentation of a Heterogeneous Watershed; Elsevier: Amsterdam, The Netherlands, 2018; Volume 10, ISBN 1976198920002.

46. Sambrakos, M.; Tsiligiridis, T. A Comparative Landscape Pattern Analysis Using Remotely-Sensed and Statistical Data to Evaluate Regional Diversity. In Proceedings of the 1st International Congress TAFE, 2003 (Information Technology in Agriculture, Food and Environment), O-GIS-33-0, Edge University, Izmir, Turkey, 7-10 October 2003.

47. Panagos, P.; Ballabio, C.; Borrelli, P.; Meusburger, K. Spatio-temporal analysis of rainfall erosivity and erosivity density in Greece. Catena 2016, 137, 161-172. [CrossRef]

48. Panagos, P.; Ballabio, C.; Borrelli, P.; Meusburger, K.; Klik, A.; Rousseva, S.; Tadić, M.P.; Michaelides, S.; Hrabalíková, M.; Olsen, P.; et al. Rainfall erosivity in Europe. Sci. Total Environ. 2015, 511, 801-814. [CrossRef]

49. Mazzoglio, P.; Laio, F.; Balbo, S.; Boccardo, P.; Disabato, F. Improving an Extreme Rainfall Detection System with GPM IMERG data. Remote Sens. 2019, 11, 677. [CrossRef]

50. Kourgialas, N.N.; Koubouris, G.C.; Karatzas, G.P.; Metzidakis, I. Assessing water erosion in Mediterranean tree crops using GIS techniques and field measurements: The effect of climate change. Nat. Hazards 2016, 83, 65-81. [CrossRef]

51. Panagos, P.; Borrelli, P.; Poesen, J.; Ballabio, C.; Lugato, E.; Meusburger, K.; Montanarella, L.; Alewell, C. The new assessment of soil loss by water erosion in Europe. Environ. Sci. Policy 2015, 54, 438-447. [CrossRef]

52. Huang, Q.; Huang, J.; Yang, X.; Ren, L.; Tang, C.; Zhao, L. Evaluating the scale effect of soil erosion using landscape pattern metrics and information entropy: A case study in the Danjiangkou reservoir area, China. Sustainability 2017, 9, 1243. [CrossRef]

53. Ouyang, W.; Skidmore, A.K.; Hao, F.; Wang, T. Soil erosion dynamics response to landscape pattern. Sci. Total Environ. 2010, 408, 1358-1366. [CrossRef]

54. Gajbhiye, S.; Mishra, S.K.; Pandey, A. Prioritizing erosion-prone area through morphometric analysis: An RS and GIS perspective. Appl. Water Sci. 2014, 4, 51-61. [CrossRef]

55. Farhan, Y.; Anaba, O. A Remote Sensing and GIS Approach for Prioritization of Wadi Shueib Mini-Watersheds (Central Jordan) Based on Morphometric and Soil Erosion Susceptibility Analysis. J. Geogr. Inf. Syst. 2016, 8, 1-19. [CrossRef]

56. Kinnell, P.I.A. Event soil loss, runoff and the Universal Soil Loss Equation family of models: A review. J. Hydrol. 2010, 385, 384-397. [CrossRef]

57. Merritt, W.S.; Letcher, R.A.; Jakeman, A.J. A review of erosion and sediment transport models. Environ. Model. Softw. 2003, 18, 761-799. [CrossRef] 